\title{
Powder Characterization for a New Selective Laser Sintering Polypropylene Material (Laser PP CP 60) after Single Print Cycle Degradation
}

\author{
Fredrick M. Mwania ${ }^{1}$, Maina Maringa², and Kobus van der Walt ${ }^{3}$ \\ ${ }^{1,2,3}$ Central University of Technology, Faculty of Engineering, Built Environment and Information Technology, \\ Department of Mechanical and Mechatronics Engineering, Private Bag X20539, Bloemfontein, 9300, South Africa.
}

ORCID: 0000-0001-8702-2496 (Frederick)

\begin{abstract}
Experiments were conducted to characterise a new polymeric powder (Laser PP CP 60) from Diamond Plastics GmbH used in selective laser sintering (SLS) additive manufacturing (AM). Three different batches of the powder were tested in the study; virgin powder, used powder, and a mixture (50\% virgin: $50 \%$ used) powder. The three batches of powder were subjected to scanning electron microscopy (SEM), differential scanning calorimetry (DSC), thermogravimetric analysis (TGA), and melt flow index (MFI) testing. Scanning electron microscopy was used to determine the morphology of particles. The distribution of powder particle sizes was established by analysing the acquired SEM images using ImageJ software. Differential scanning calorimetry was used to determine the peak melting point, degree of crystallisation, and the sintering window of the powder. Thermogravimetric analysis was utilised to determine temperatures of degradation of the powder considered in the study. Lastly, MFI testing was used to determine the variation of flowability of the powder. It was found that the three batches of powder considered showed poor, but allowable morphology and particle size distribution. The sintering window of the virgin Laser PP CP 60 polypropylene powder increased after a single cycle of printing by $28 \%$, from $21.04^{\circ} \mathrm{C}$ (virgin powder) to $26.95^{\circ} \mathrm{C}$ (used powder). The sintering window was lower than that for polyamide polymer, which might have contributed to the high shrinkage rates observed during processing of the material, as a narrow sintering window results in difficulties of regulating the cooling rate of the printed parts. The three batches of powder showed high degradation temperatures, which makes the material suitable for SLS processing. Finally, the three batches of powder showed low values of MFI, which indicates that the molten material has a high viscosity. This explains the difficulties experienced in processing the material.
\end{abstract}

Keywords: Powder characterization, morphology of particles, size distribution of powder particles, peak melting point, degree of crystallisation, sintering window, degradation temperatures, flowability

\subsection{INTRODUCTION}

Selective laser sintering is one of the commonly used AM technologies for polymers. The process involves fusion of powder particles using a laser beam to bind layer upon layer of a material to form 3D components [1]. There are, however, a limited variety of polymeric materials suitable for SLS processing. Approximately $90 \%$ of polymers used in the SLS process are either polyamide 12 (PA 12) or its blends [2]. This is the case because the manufacturing of polymers using SLS is influenced by elaborate processing parameters and conditions, as well as, intricate requirements of material properties that are not easy to meet [2]. Therefore, there is a need to increase the material array for SLS polymers.

Selective laser sintering progresses in three stages. The first stage involves pre-heating of the powder material, the second phase fusing the powder particles using a laser beam, and the last step, regulated cooling [3]. Polymers are pre-heated before SLS to ensure that the laser beam is used to only tip the material over into the molten state without the use of excessive energy, which might otherwise result in excessive degradation of the polymers $[3,4,5,16]$. Additionally, the cooling process should be controlled to avoid rapid recrystallization, which results in curling and distortion and, therefore, reduction of the dimensional accuracy of printed parts. Semi-crystalline polymers are pre-heated to temperatures just below their melting points, whereas the amorphous polymers are heated to temperatures just below their glass transition point because the latter type of polymers does not have a definite melting point [3]. It is worthy to note that during laser sintering, the powder bed temperature should be kept constant between melting and crystallization points (sintering window) to avoid rapid recrystallization [3]. The last step, which is regulated cooling process should be controlled to avoid rapid recrystallization, which results in curling and distortion and, therefore, reduction of the dimensional accuracy of printed parts. Controlled cooling also maximizes consolidation of powder melt [10]. A successful process is also achieved when suitable process parameters, such as optimum laser power, hatch distance, layer thickness, and scanning velocity, are utilised.

Apart from the process parameters, the properties of polymer also affect their ability to be processed. These properties are classified into either intrinsic or extrinsic properties as shown 
International Journal of Engineering Research and Technology. ISSN 0974-3154, Volume 13, Number 11 (2020), pp. 3342-3358

(C) International Research Publication House. https://dx.doi.org/10.37624/IJERT/13.11.2020.3342-3358

in Figure 1.

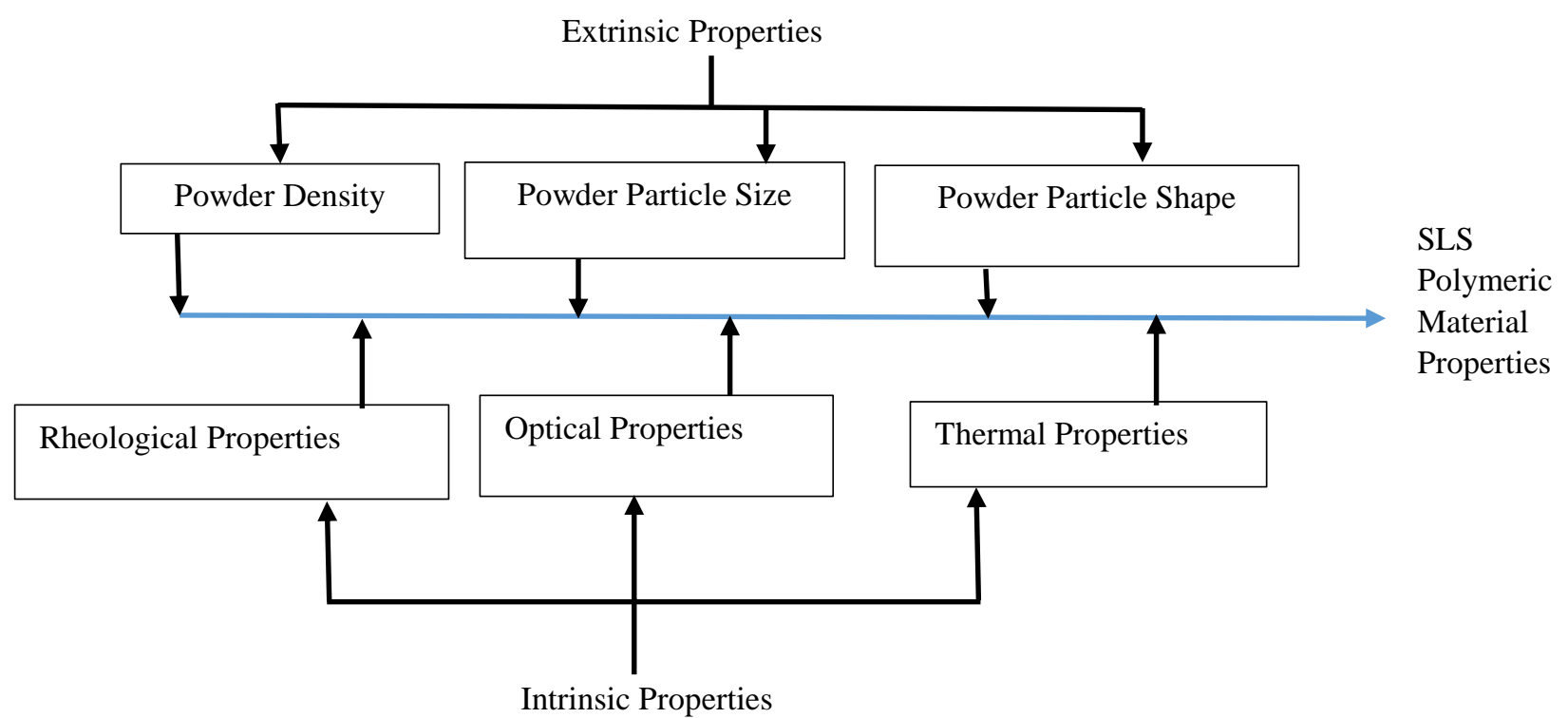

Figure 1. The Intrinsic and Extrinsic Properties of Polymeric Powder Material Used in SLS AM [2]

The extrinsic properties include factors such as powder density, powder particle shape, and powder particle size [6]. Suitable polymer powder particle sizes lie between 20 and 80 microns [6]. Furthermore, the powder particles should possess almost a spherical shape to promote free-flowing behaviour, which encourages spreading of the powder. Figure 2 illustrates suitable shapes for SLS polymers. Moreover, polymer powder should have a suitable density (comparable to a density of $1.01 \mathrm{~g} / \mathrm{cm}^{3}$ for PA 12 powder) to ensure that the built parts have appropriate part properties $[2,6,7]$.

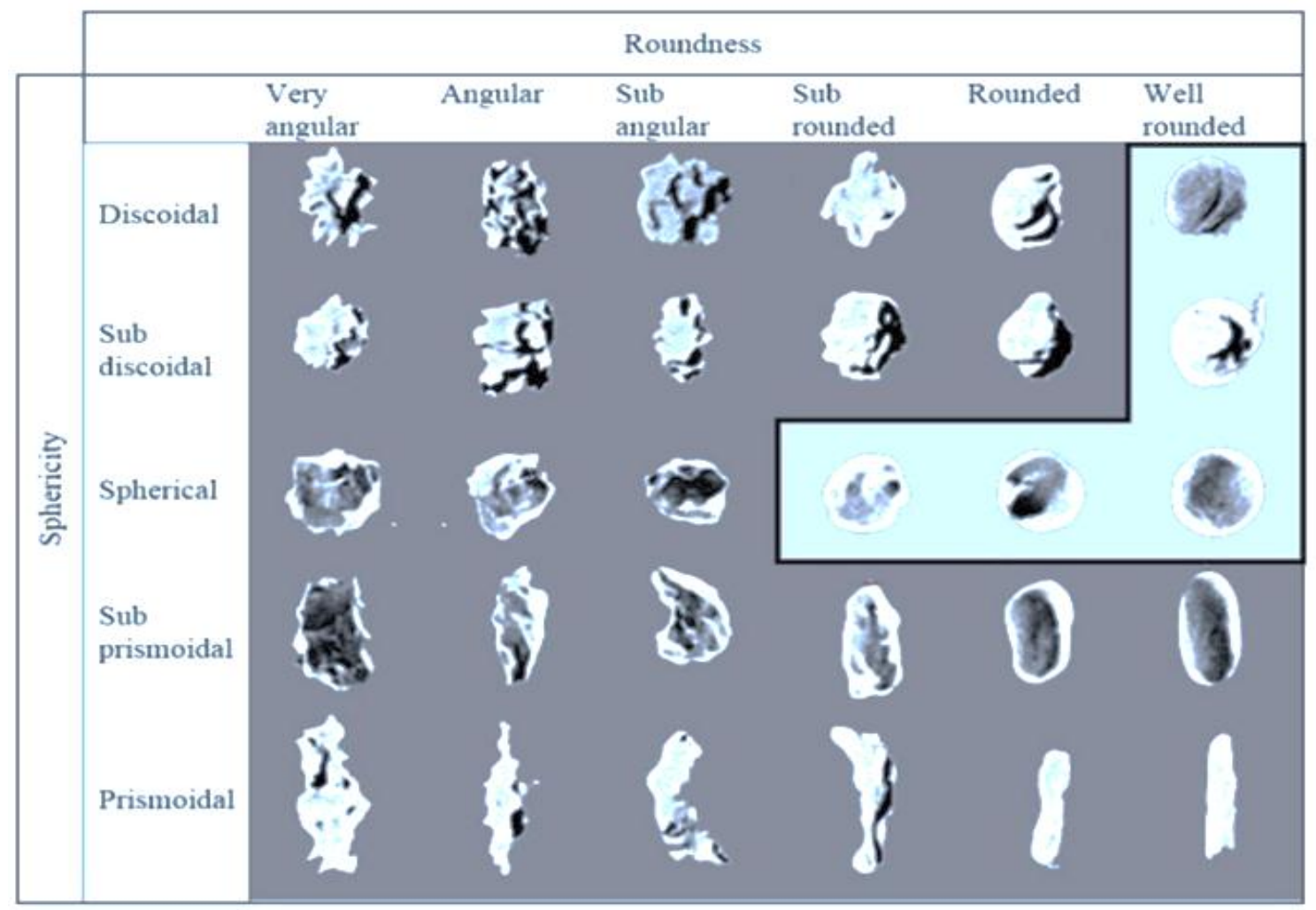

Figure 2. Various Types of Powder Morphology - Particles in Brighter Area are Considered Suitable for SLS [19] 
Intrinsic properties include rheological, optical, and thermal behaviour. Suitable polymeric materials, for SLS, should have a wide sintering window to facilitate easy maintenance of the build chamber temperatures [2,7]. Besides, the materials should have a low melting temperature to avoid the use of high energy density, which results in degradation of material [7]. The rheological properties should be such that, the viscosity of the powder should not be too high or too low. Extremely high viscosity of the powder hinders free-flowing behaviour of the powder and arising melt, while too low viscosity affects coalescence of the material, the last which impacts on the mechanical integrity of the manufactured parts due to introduced porosity $[2,4,15]$. Ideally, suitable SLS polymeric materials should have low melt viscosity and low surface tension to ensure sufficient coalescence of material without extra compacting $[2,6]$. Furthermore, the surface tension of the melt influences the sinking depth of the melt into the powder bed, which in turn influences the dimensional accuracy and surface roughness of printed parts [8]. Lastly, most polymers absorb the $\mathrm{CO}_{2}$ laser beam and therefore melt because their optical properties are suitable to the use of this beam [3].

Various studies have shown that repeated re-use of polymeric material results in degradation (material aging) [9,13,14]. Consequently, the material properties of SLS polymers reduce with the number of re-use cycles. In this regard, experiments were performed to characterise three different batches of Laser PP CP 60 polypropylene powder from Diamond Plastics $\mathrm{GmbH}$ (virgin material, used material (one cycle), and a mixture $(50 \%$ virgin: $50 \%$ used powder). The study considered changes in particle morphology, the peak melting point, the degree of crystallization, the sintering window, the degradation temperature, and the flowability.

\subsection{LITERATURE REVIEW}

The suitability of polymers in SLS is dependent on several material properties. Moreover, the material-characteristics are affected by repeated use of a given batch of powder. As such, it is recommended to characterize virgin or used powder polymeric materials to ascertain their suitability. Dadbakhsh et al., [10], compared virgin and aged PA 12, where the authors established that after ageing, the size of the powders remained almost unchanged $(55-60 \mu \mathrm{m})$. The authors also found that cracks developed on the surfaces of the powder particles at high temperatures, which might be due to evaporation of alcohol or absorbed moisture. It was concluded that the morphological changes might reduce flow and aggravate formation of orange peel. Dadbakhsh et al., [10], found that the melting shoulder interval increased from $7.9^{\circ} \mathrm{C}$ for virgin to $10.8^{\circ} \mathrm{C}$ for aged PA 12 powder. Besides, the viscosity of the polymeric powder was found to increase with aging, probably due to cross-linking of the carbon chains, which increases molecular weight. The authors concluded that, the properties of the PA 12 polymeric powder changed with aging.

Gornet et al., [11], investigated the effects of repeated reuse of SLS PA 12 powder from 3D Systems Corporations. The authors measured the flow characteristics using an extrusion plastometer, where it was established that melt flow rate decreased with each build cycle as indicated by Figure 3.
Besides, the melting point of the material was examined using differential scanning calorimetry, where it was concluded that melting temperature increased with printing cycles, as shown in Figure 4. Kuehnlein et al. [14], found that the viscosity of PA 12 increases with processing time. The melt flow rate of the powder used by the authors reduced from $28 \mathrm{~cm}^{3} / 10 \mathrm{~min}$ to 7 $\mathrm{cm}^{3} / 10$ min after 4 hours of oven storage at $170^{\circ} \mathrm{C}$. Aldahsh [25], established that that the viscosity of a cement/PA 12 composite increased with processing time and temperature. It is evident from the foregoing reviews that the characteristics of PA12 polymeric powder changes with re-use cycles.

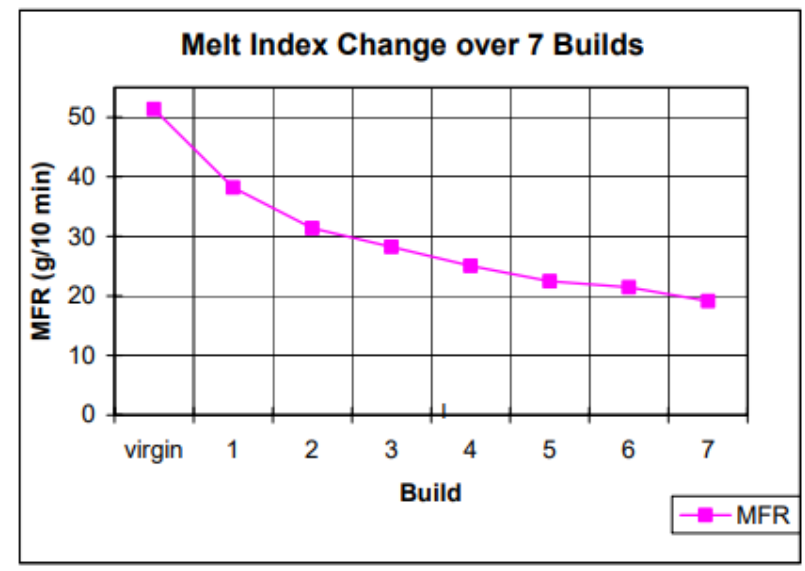

Figure 3. The Trend of Melt Flow Rate of PA 12 Powder with Re-Use Cycles [11]

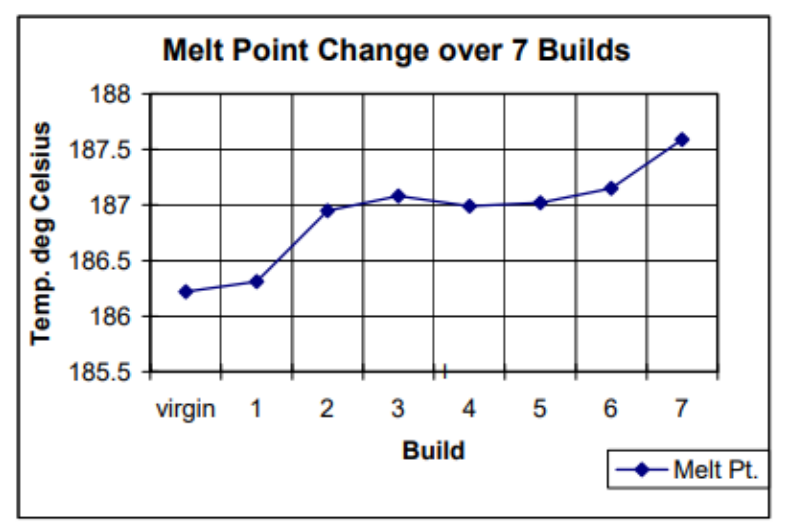

Figure 4. The Trend of Melting Point of PA 12 Powder with Re-Use Cycles [11]

Berretta et al., [15], investigated the particle size distribution, morphology, and the flowability of virgin and mixed 50/50 virgin/used SLS PA 12 powder. The authors found that the roundness of virgin (0.69) is higher than that of $50 / 50$ virgin/used (0.68) PA 12 powder, which indicates that virgin material is more spherical compared to used powder. The slight difference (0.01), indicates that particle size is not significantly influenced by SLS process, which confirms the findings by Dadbakhsh et al., [10]. Besides, it was found that angle of repose (AOR) of a virgin PA 12 powder (33.1) was lower compared to that of 50/50 virgin/used material (38.4). Therefore, the flowability of virgin PA 12 powder is better 
compared to that of 50/50 virgin/used material. Hence, PA 12 powder undergoes changes when processed since flowability is subject to particle size distribution, particle shape, and particle surface features.

Schmidt et al., [20], reviewed the effect of particle size, morphology, and particle surface characteristics on flowability, packing density, and tribo-charging of PA 12 for virgin and aged powder. The authors noted the inferior flowability of aged material, which is subject to the powder particle shape, that impedes processability of polymers. It was also noted that the typical particle sizes of SLS polymers should be between 45 and $90 \mu \mathrm{m}$. Furthermore, PA2200 powder polymer is characterized by a narrow particle size distribution, which promotes flowability and dense packing of the printed parts. Relatively rougher particle surface reduces inter particle forces, which also encourages powder flowability. The authors also observed that virgin powder showed less tribo charging as opposed to aged materials. High tribo charges encourage powder agglomeration, which reduces flowability. Lastly, virgin polymeric powder is characterized by good spreading and deposition, which guarantees homogenous powder layers and low porosity. Hence, parts printed using virgin PA 12 powder exhibit higher packing density compared to components made using used material. Overall, it can be concluded from the foregoing information that the material properties of polymeric powders are affected by aging.

\subsection{MATERIALS AND METHODS}

In this study, a polypropylene powder grade (Laser PP CP 60) from Diamond Plastics GmbH was appraised in three different batches (i) virgin material, (ii) used material (one cycle), and (iii) used (50\%)-virgin (50\%) material mixture. The used powder (a mixture of the cake and overflow powder) was exposed to a single SLS cycle, where the building chamber and extraction chamber temperatures of about $125^{\circ} \mathrm{C}$ were applied. The used-mixed powder was obtained by mixing $5 \mathrm{~kg}$ of virgin material with $5 \mathrm{~kg}$ of used material. The three forms of powder were subjected to SEM, DSC, TGA, and MFI testing.

\subsection{Selective Laser Sintering (SLS) Processing}

Selective laser sintering was performed on an EOSINT P380 machine with a $\mathrm{CO}_{2}$ laser beam. The powder used was tested after a single printing of different standard tensile specimens (ASTM D 68), shown in Figure 5. Table 1 summarizes the parameters used to print the different samples.

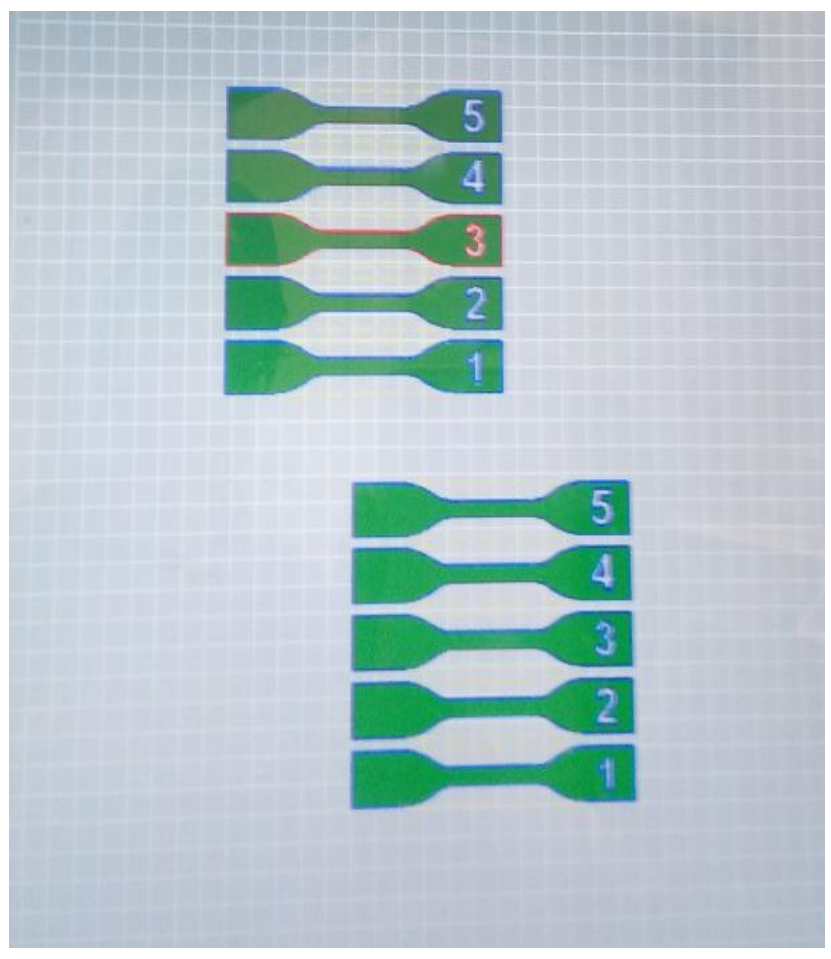

Figure 5. Different Standard Tensile Specimens (ASTM D 638)

Table 1: The process parameters used to build different standard tensile specimens (ASTM D 638)

\begin{tabular}{|c|c|c|c|c|c|c|c|c|}
\hline Specimen & $\begin{array}{c}\text { Temp. of the } \\
\text { removal } \\
\text { chamber }\left({ }^{\circ} \mathrm{C}\right)\end{array}$ & $\begin{array}{c}\text { Temp. of the } \\
\text { building } \\
\text { chamber }\left({ }^{\circ} \mathrm{C}\right)\end{array}$ & $\begin{array}{c}\text { Layer } \\
\text { thickness } \\
(\mathrm{mm})\end{array}$ & $\begin{array}{c}\text { Hatch } \\
\text { distance } \\
(\mathrm{mm})\end{array}$ & $\begin{array}{c}\text { Scanning } \\
\text { speed fill } \\
(\mathrm{mm} / \mathrm{s})\end{array}$ & $\begin{array}{c}\text { Laser } \\
\text { power fill } \\
(\mathrm{W})\end{array}$ & $\begin{array}{c}\text { Scanning speed } \\
\text { contour/edges } \\
(\mathrm{mm} / \mathrm{s})\end{array}$ & $\begin{array}{c}\text { Laser power } \\
\text { contour/ } \\
\text { edges }(\mathrm{W})\end{array}$ \\
\hline 1 & 125 & 125 & 0.15 & 0.25 & 2000 & 23.3 & 700 & 9.7 \\
\hline 2 & 125 & 125 & 0.15 & 0.25 & 2500 & 25.5 & 700 & 73.0 \\
\hline 4 & 125 & 125 & 0.15 & 0.25 & 2500 & 30.2 & 13.0 \\
\hline 5 & 125 & 125 & 0.15 & 0.25 & 3500 & 31.5 & 1500 & 10.7 \\
\hline
\end{tabular}

\subsection{Scanning Electron Microscopy}

Scanning electron microscopy was conducted using a JSM6610LV scanning electron microscope. The samples were first coated with about $6 \mathrm{~nm}$ of carbon to avoid the effects of supercharging, which affects the quality of the images obtained. After this, images were obtained using the SEM software and then the morphology of the particles determined. The accelerating voltage was first set at $25 \mathrm{kV}$, which was later changed to $30 \mathrm{kV}$ to obtain clearer images. Figure 6 shows the 
carbon coater machine, while Figure 7 shows the SEM equipment used in this study.

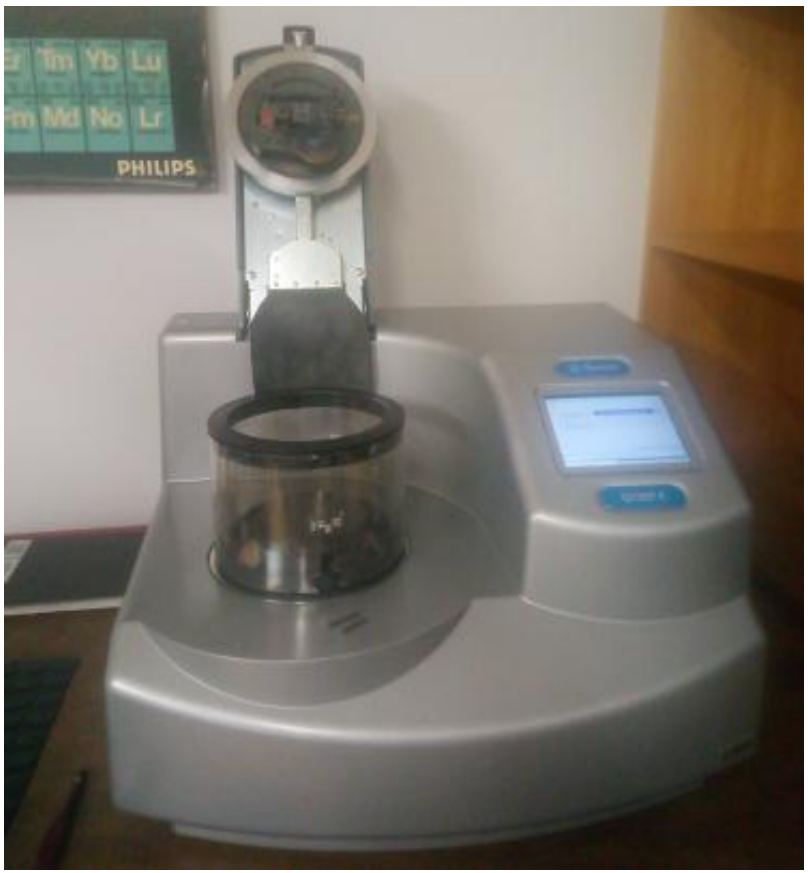

Figure 6. A Carbon Coater (Department of Geology, University of Free State, South Africa)

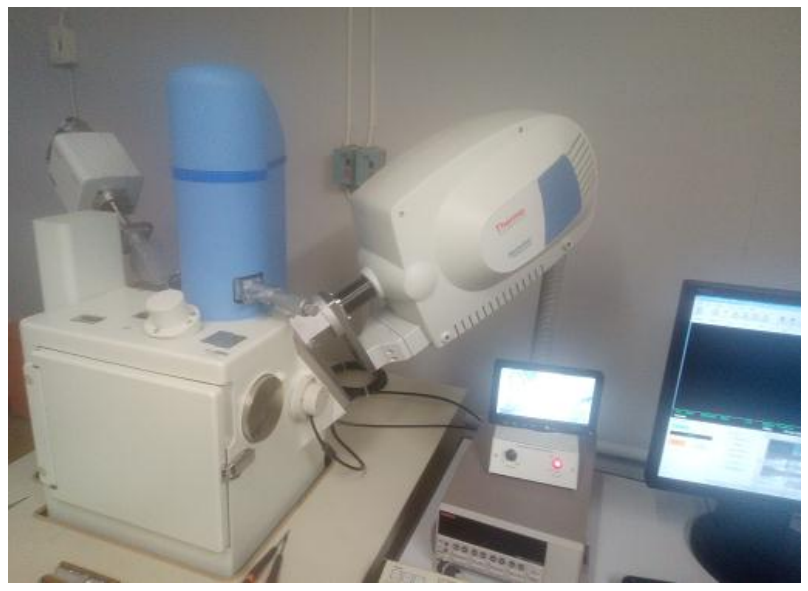

Figure 7. A JSM-6610LV Scanning Electron Microscope (Department of Geology, University of Free State, South Africa)

\subsection{Differential Scanning Calorimetry Testing}

Differential scanning calorimetry was conducted on single samples for three cycles using the Mettler Toledo DSC equipment shown in Figure 8, and in an atmosphere of nitrogen. Approximately $6 \mathrm{~g}$ of powder was utilised for each of the three samples considered in the experiment. Furthermore, the heating and cooling cycles were performed between room temperature and $180^{\circ} \mathrm{C}$ and at a rate of $10{ }^{\circ} \mathrm{C} / \mathrm{min}$. The heating and cooling phases were undertaken in a flow of $50 \mathrm{ml} / \mathrm{min}$ of nitrogen. The enthalpy of fusion for $100 \%$ polypropylene material of about $209 \mathrm{~J} / \mathrm{g}$ is used here as a reference [18].

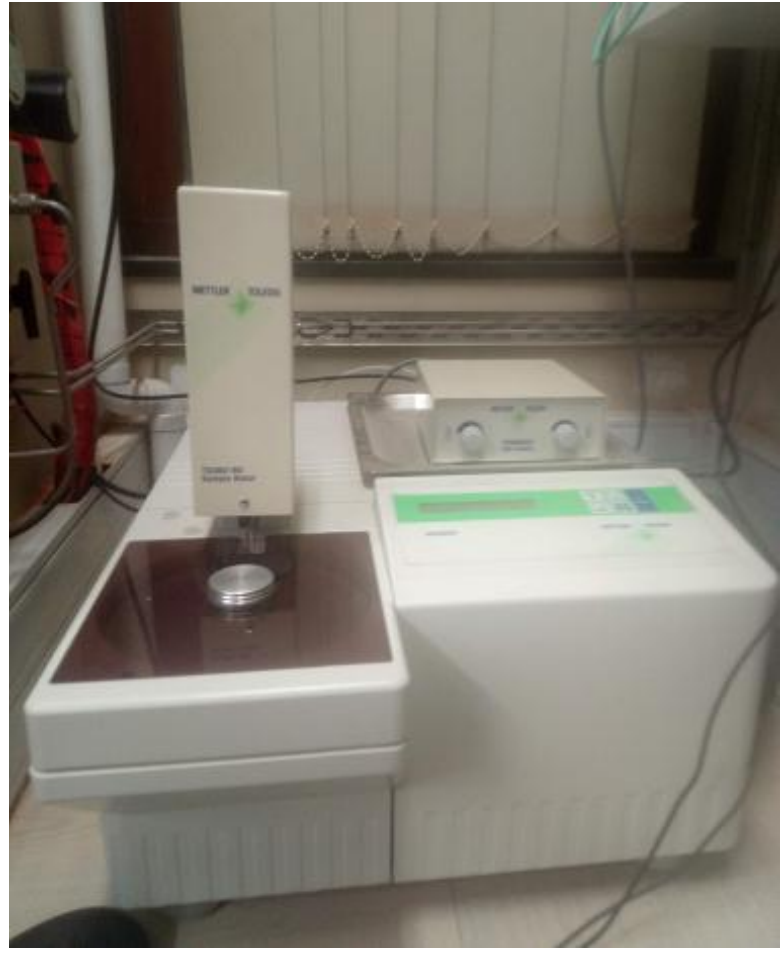

Figure 8. A Mettler Toledo DSC (821e/700) Equipment (Department of Geology, University of Free State, South Africa)

\subsection{Thermogravimetric Analysis}

A Mettler Toledo (TGA/SDTA851) TGA equipment such as the one shown in Figure 9 was employed in this analysis. The powder materials were loaded into the machine using crucibles. Powder samples of approximately $9.04 \mathrm{~g}, 10.30 \mathrm{~g}$, and $8.79 \mathrm{~g}$ were used for the virgin material, used material, and usedvirgin mixture material respectively. The samples were heated at a rate of $10{ }^{\circ} \mathrm{C} / \mathrm{min}$ from room temperature up to $550^{\circ} \mathrm{C}$ in an atmosphere of nitrogen.

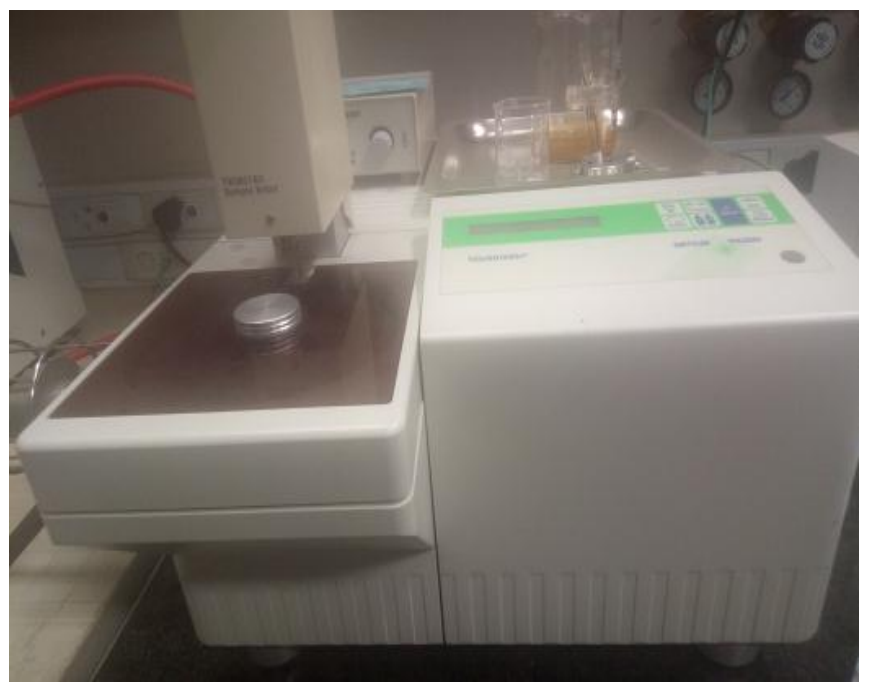

Figure 9. A Mettler Toledo (TGA/SDTA851) TGA Equipment (Department of Geology, University of Free State, South Africa) 


\subsection{Melt Flow Index Testing}

Melt flow index testing was done using the MFI tester from Ametex Ltd. Shown in Figure 10, which consists of a $2.16 \mathrm{~kg}$ test load, charging rod, cleaning rod, tungsten carbide die with a capillary diameter of $2.095 \mathrm{~mm}$ and a die ejector. The testing process began by cleaning the die using the cleaning tool and a cotton cloth. After cleaning the die, about 6 grams of powder sample was loaded into it. After which, the die ejector with a mounted test load was inserted into the die and the powder in the die preheated for about 6 minutes at $230^{\circ} \mathrm{C}$ (as recommended by the manufactuer), then the time taken by the die ejector to move between two marked points measured. The mass of the ejected polymer material was determined using an electronic weighing machine, and the value of MFI calculated using Equation 1.

$$
M F I=\frac{600+m}{t}
$$

where, the symbols $m$ and $t$ stand for the measured mass of ejected material and time taken to eject the material between the marked points of the die ejector, respectively.

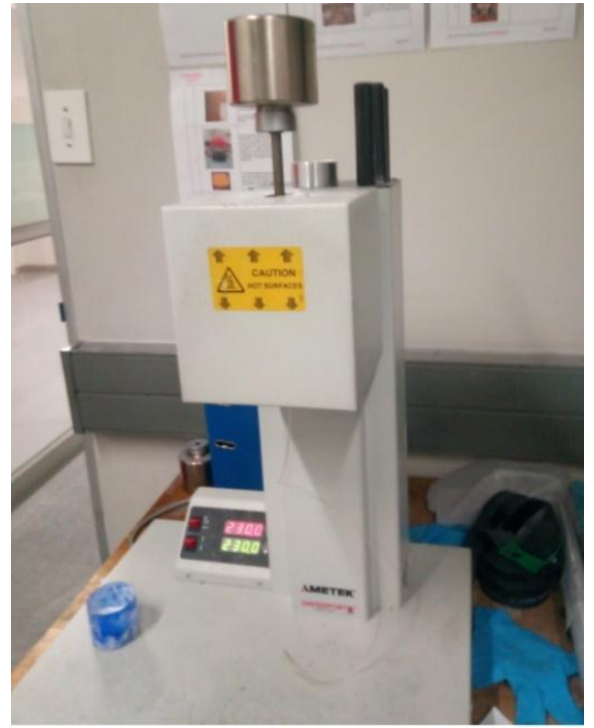

Figure 10. MFI Tester from Ametex Ltd (Centre for Rapid Prototyping and Manufacturing, Central University of Technology, Free State)

\subsection{RESULTS AND ANALYSIS}

\subsection{Powder Morphology from the Results of SEM}

Figures 11, 12, and 13 show the morphology, at different magnifications, of samples of virgin, used, and used-virgin PP powder, respectively.
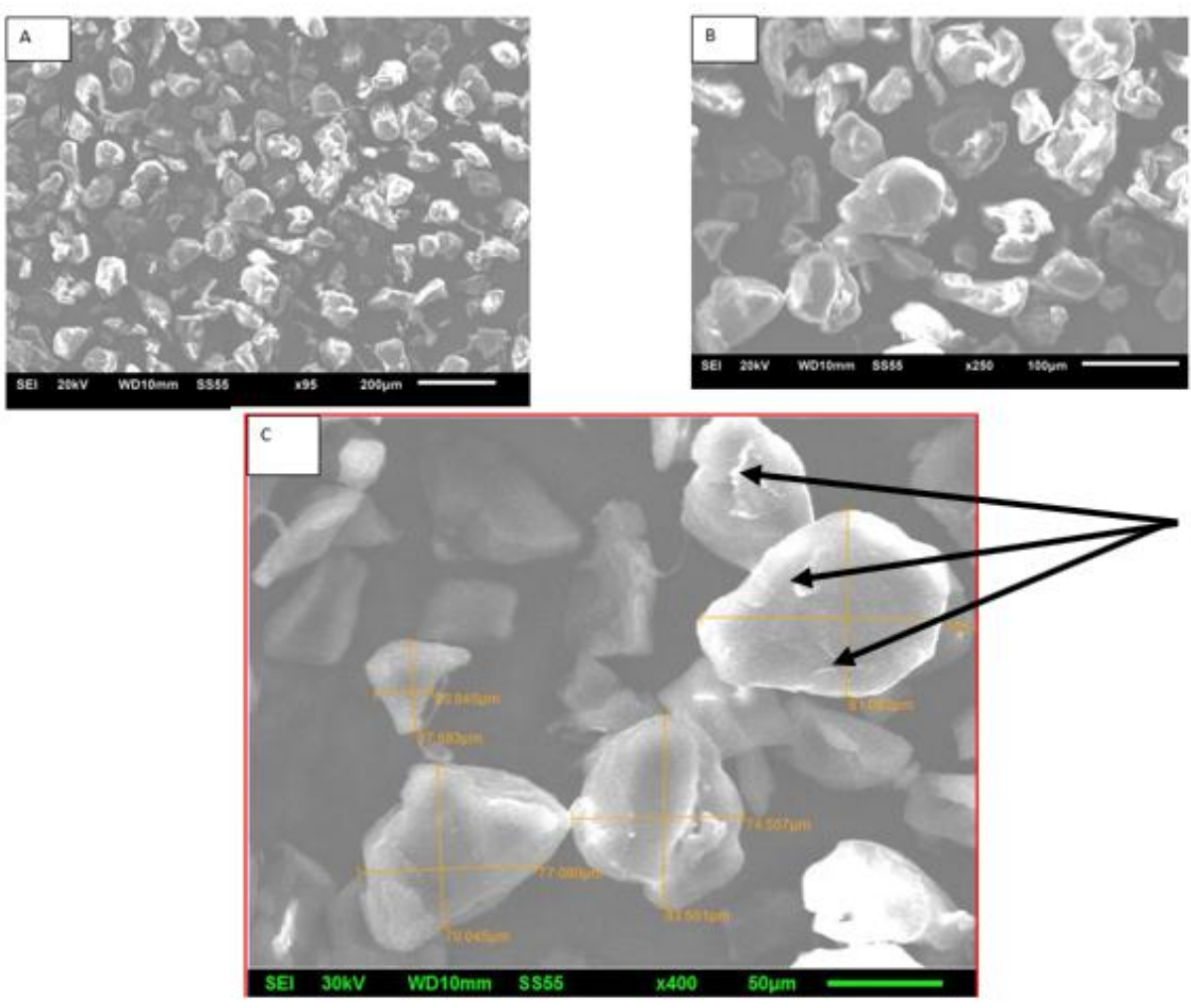

Flakes on the surface of a powder particles

Fig. 11. Powder Morphology of Virgin Laser PP CP 60 Polypropylene Powder 


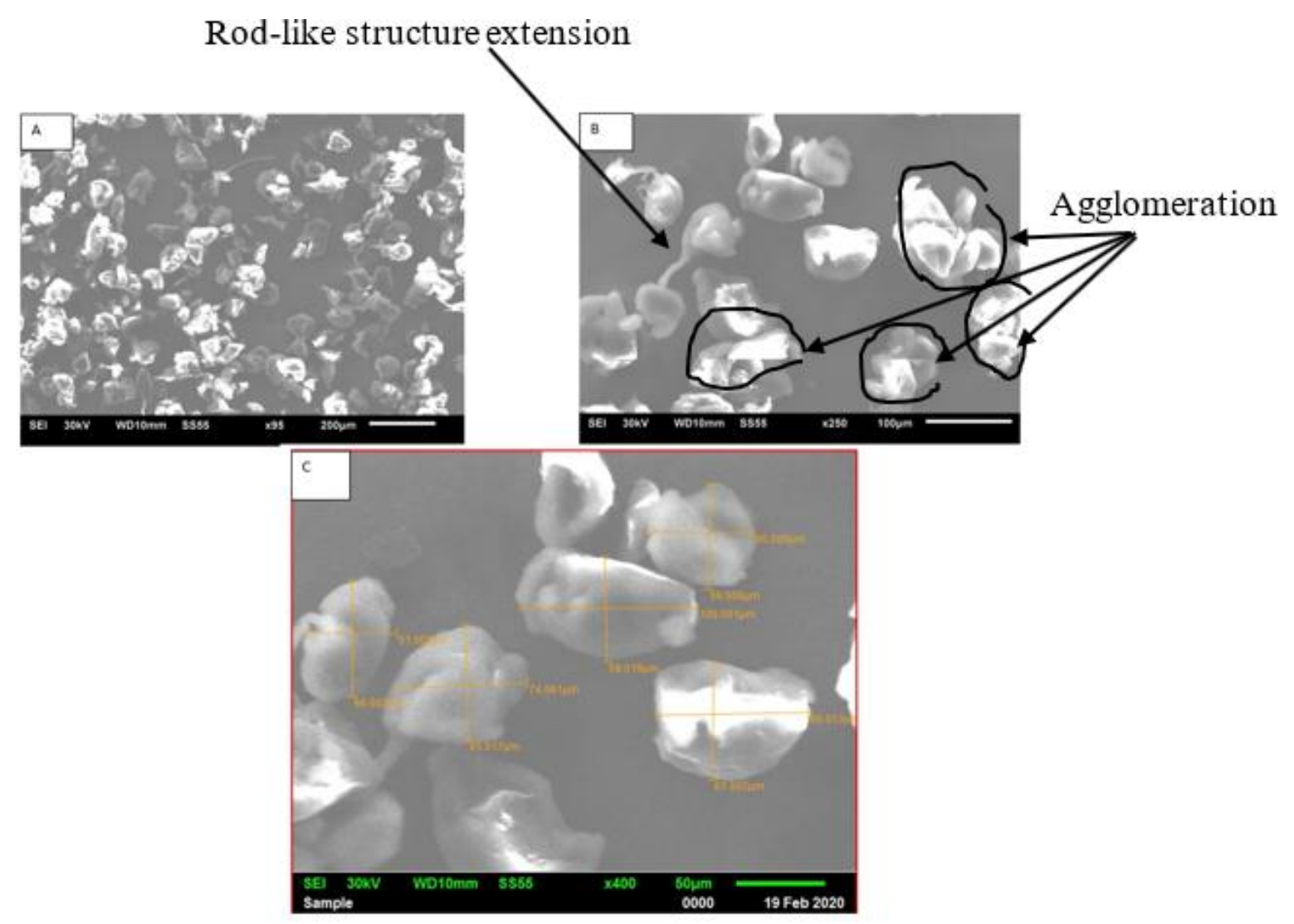

Fig. 12. Powder Morphology of Used (1 Cycle) Laser PP CP 60 Polypropylene Powder
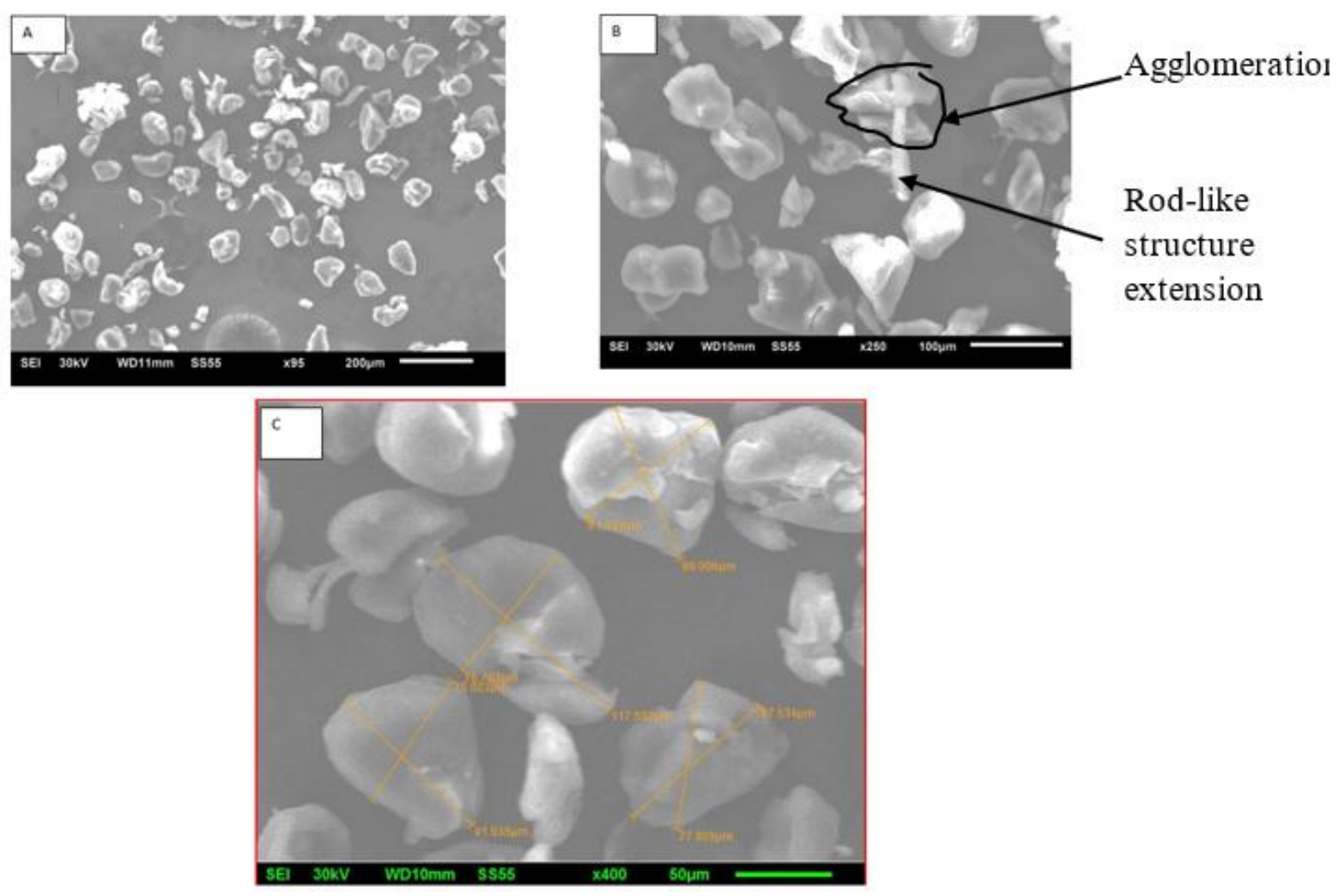

Fig. 13. Powder Morphology of Used-Virgin Laser PP CP 60 Polypropylene Powder Mixtur 
Figures 11, 12, and 13 illustrate that the powder particles of all three batches of Laser PP CP 60 polypropylene are irregularly shaped. Selective laser sintering powders should be spherically shaped to ensure free-flowing behaviour and the fact that the three batches of powder all exhibited poor flowability during processing is probably due to their irregularly shaped particles $[21,24]$.

The powder particles for the virgin material were not clumped as evident in Figure 11a. However, for the used powder, agglomeration of powder particles was established. Figure $13 \mathrm{~b}$ shows that mixing used powder with virgin material ameliorates the effects of agglomeration, since there was reduction in the number of agglomerated powder particles. By comparing Figures $12 \mathrm{~b}$ and $13 \mathrm{~b}$, it is evident that the number of agglomerates for the same area reduces from 4 to 1 . It was also observed that there were extension features that altered the shapes of the particles into tadpole (rod-like) shapes as shown in Figure 12b. The origin of the extensions is not clear, but they might be attributed to the shearing action of the technique used to manufacture the powder. Mys et al. [26] similar morphological inconsistence when manufacturing syndiotactic polystyrene using ball and rotor milling powder production methods.

The SEM images showed that the new Laser PP CP 60 polypropylene powder exhibits relatively smooth surfaces. However, rough patches and flakes were also observed on the surface of the powder particles, as illustrated by Figure 11c, which might have also contributed to the poor flowability of the new Laser PP CP 60 polypropylene powder. The new Laser PP CP 60 polypropylene powder needs to be improved by altering its morphology to facilitate the flowability of the material. However, based on the information provided in Figure 11, the powder is still processable with AM.

The SEM micrographs did not identify any flow and antistatic agents, such as silica and glass beads, which are commonly used in polymeric materials to improve their flowability and reduce the effects of electrostatic charges. This in addition to the irregularly shaped particles and incidences of particle agglomeration explains the flowability and processability difficulties that were observed with the new Laser PP CP 60 polypropylene powder. The powder was only able to print flat tensile specimen because curling led to dislodging of parts from the building chamber, which prompted stoppage of the SLS process.

\subsection{Distribution of Particle Sizes from the Results of SEM}

Table 2 and Figures 14, 15, and 16 illustrate the distribution of particle sizes of virgin, used, and used-virgin PP powder batches, respectively. The particle size distribution was determined using ImageJ software.

Table 2. Particle size distribution for the three batches of powders

\begin{tabular}{|c|c|c|c|}
\hline Powder batch & $\begin{array}{c}\text { Powder particle } \\
\text { distribution }\end{array}$ & $\begin{array}{c}\text { Mean } \\
\text { powder } \\
\text { particle size }\end{array}$ & $\begin{array}{c}\text { Standard } \\
\text { deviation of } \\
\text { the particle } \\
\text { size }\end{array}$ \\
\hline $\begin{array}{c}\text { Virgin } \\
\text { powder }\end{array}$ & $25.0-120 \mu \mathrm{m}$ & $63.7 \mu \mathrm{m}$ & $24.5 \mu \mathrm{m}$ \\
\hline $\begin{array}{c}\text { Aged powder } \\
\text { (one cycle) }\end{array}$ & $19.0-105.0 \mu \mathrm{m}$ & $65.7 \mu \mathrm{m}$ & $23.7 \mu \mathrm{m}$ \\
\hline $\begin{array}{c}\text { Mixed } \\
\text { powder }\end{array}$ & $26.2-115.5 \mu \mathrm{m}$ & $64.0 \mu \mathrm{m}$ & $21.1 \mu \mathrm{m}$ \\
\hline
\end{tabular}

The particle size range for all the batches of powder considered was between 19 and $120 \mu \mathrm{m}$, as indicated in Table 2. This powder particle size distribution is slightly above the recommended range of between $20 \mu \mathrm{m}$ and $80 \mu \mathrm{m}$ [6] or 45 and $90 \mu \mathrm{m}[20]$. However, it is still acceptable for processing in the SLS technique because the average size of the virgin $(63.7 \mu \mathrm{m})$, the used powder $(65.7 \mu \mathrm{m})$, and used-virgin mixture $(64.0 \mu \mathrm{m})$ was at least two times smaller than the build layer thickness of EOS P3800 machine of between $100-150 \mu \mathrm{m}$. The build layer thickness should be at least two times the average size of powder particle to ensure that powder fusion happens on direct contact with laser beam, rather than having particle-to-particle conduction, which results in partial coalescence, resulting in mechanically weak components [15]. The mean particle size of the virgin powder increased from $63.7 \mu \mathrm{m}$ to about $65.7 \mu \mathrm{m}$ (a $3.14 \%$ increase), upon one cycle of printing, which then reduced to $64.0 \mu \mathrm{m}$ (a $2.59 \%$ increase) after mixing of the two in equal volumes. This confirms the summation by Dadbakhsh et al., [10], that particle size of polymeric powder particles is not significantly influenced by SLS process.

The bar charts in the three figures represent the actual particle size distribution, whereas the normal curve illustrates the expected particle size distribution. The actual particle size distribution is supposed to follow the normal curve. However, for all the three batches, the actual particle size distribution was not well defined, which indicates the irregularity of the particle size distribution of Laser PP CP polypropylene powder. 
International Journal of Engineering Research and Technology. ISSN 0974-3154, Volume 13, Number 11 (2020), pp. $3342-3358$

(C) International Research Publication House. https://dx.doi.org/10.37624/IJERT/13.11.2020.3342-3358

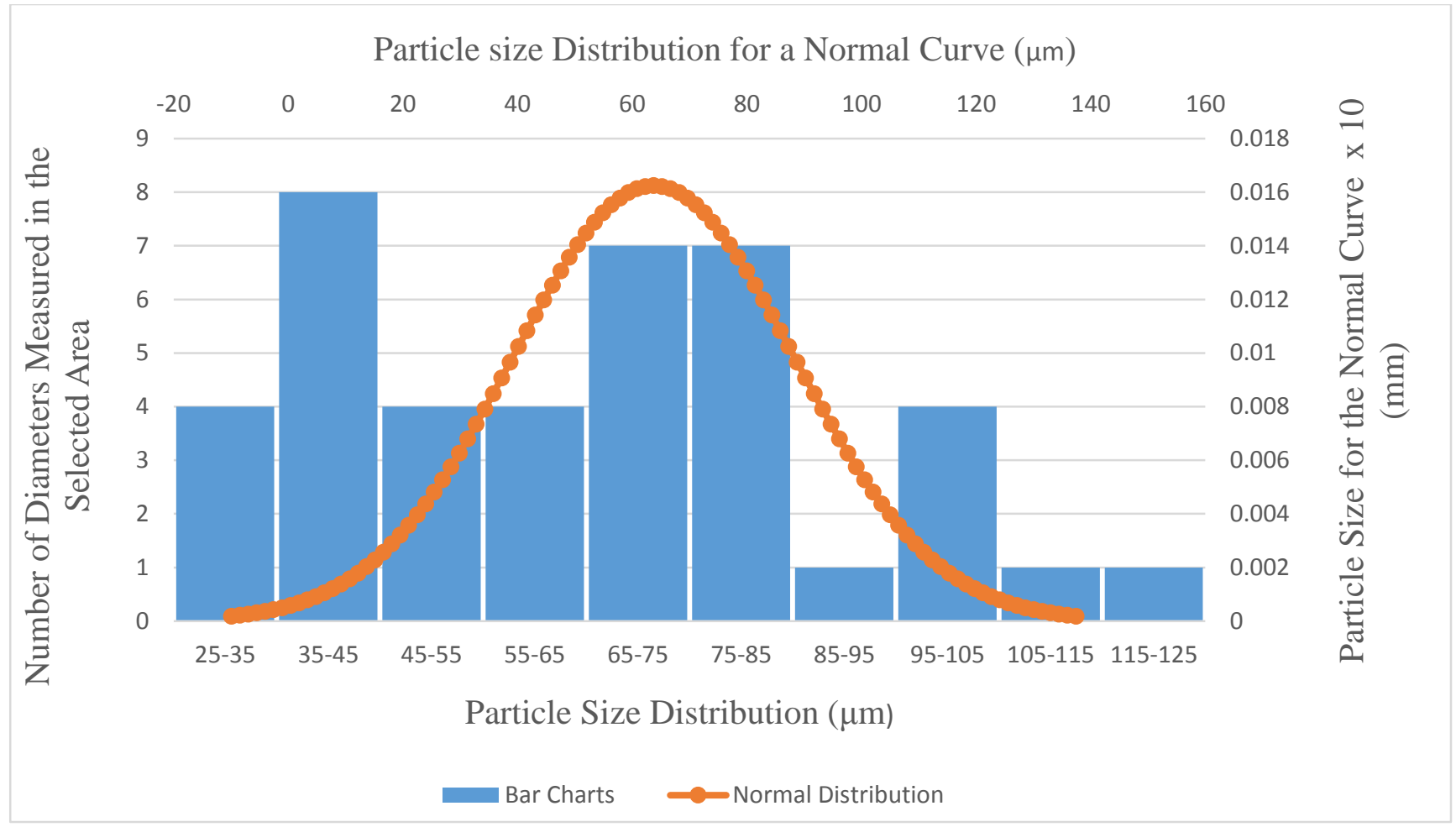

Figure 14. Distribution of Particle Sizes of the Virgin Laser PP CP 60 Polypropylene Powder

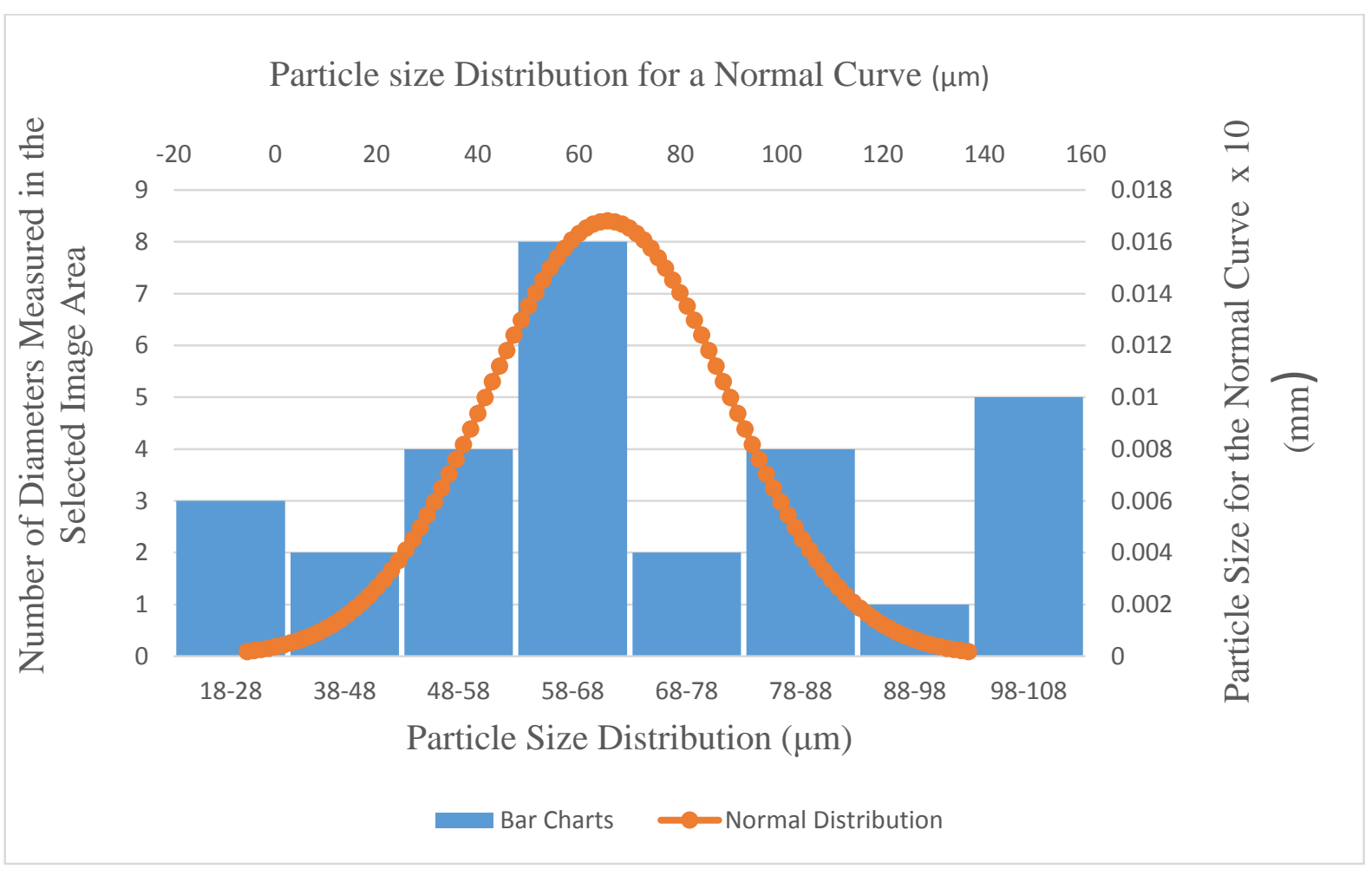

Figure 15. Distribution of Particle Sizes of the Used (1 Cycle) Laser PP CP 60 Polypropylene Powder 


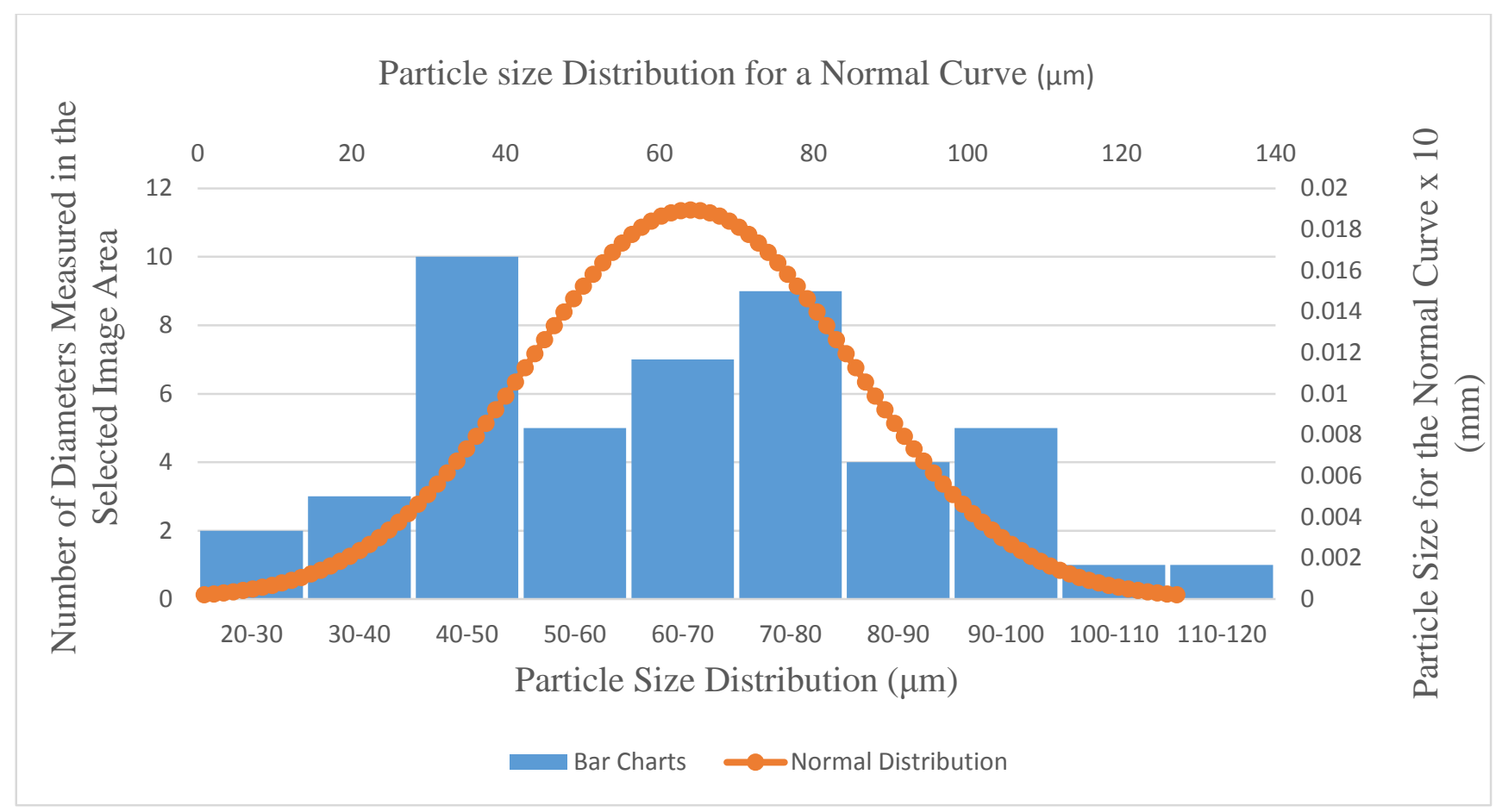

Figure 16. Distribution of Particle Sizes of the Used-Virgin Powder Laser PP CP 60 Polypropylene Powder

It is observed from these three figures that the as-received virgin, used, and used/virgin mixed powders all exhibit irregular powder size distribution, since most of the bar charts do not fall within the expected normal distribution curve. Schmid et al. [23], suggested that materials with irregular power distribution exhibit medium flowability characteristics.

The skewness values of the virgin, used, and used/virgin mixed powder particle size distribution were calculated as 0.445886 , -0.15085 , and 0.23085 , respectively. The used powder showed the smallest variation in the distribution of particle sizes of all three batches, while the virgin powder exhibited the highest skewness.

\subsection{The Differential Scanning Calorimetry (DSC) Testing}

Differential Scanning Calorimetry was used to investigate the thermal properties of the three batches of polypropylene powder in respect of peak melting point, peak crystallisation point, onset of melting, onset of crystallisation, melting shoulder interval, crystallisation shoulder interval, sintering window, and degree of crystallinity. The results of this analysis are presented in Figures $17-19$ and Table 3.

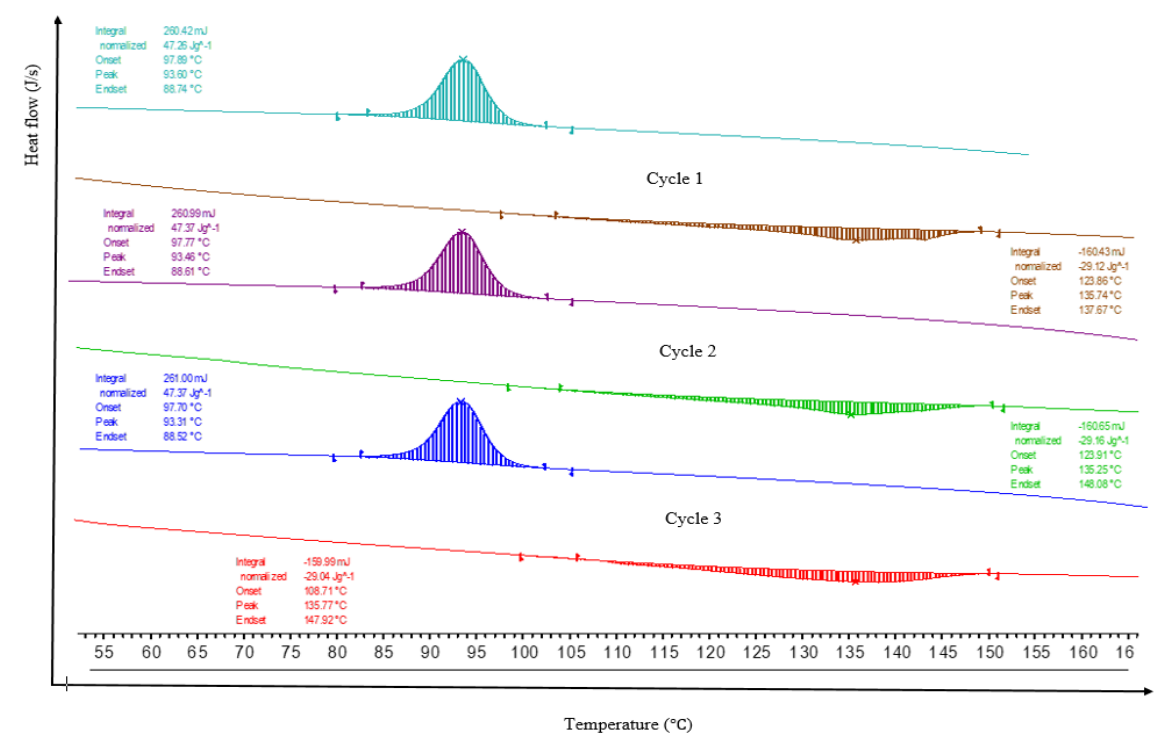

Figure 17. Differential Scanning Calorimetry Thermogram of the Virgin Powder 
International Journal of Engineering Research and Technology. ISSN 0974-3154, Volume 13, Number 11 (2020), pp. $3342-3358$

(C) International Research Publication House. https://dx.doi.org/10.37624/IJERT/13.11.2020.3342-3358

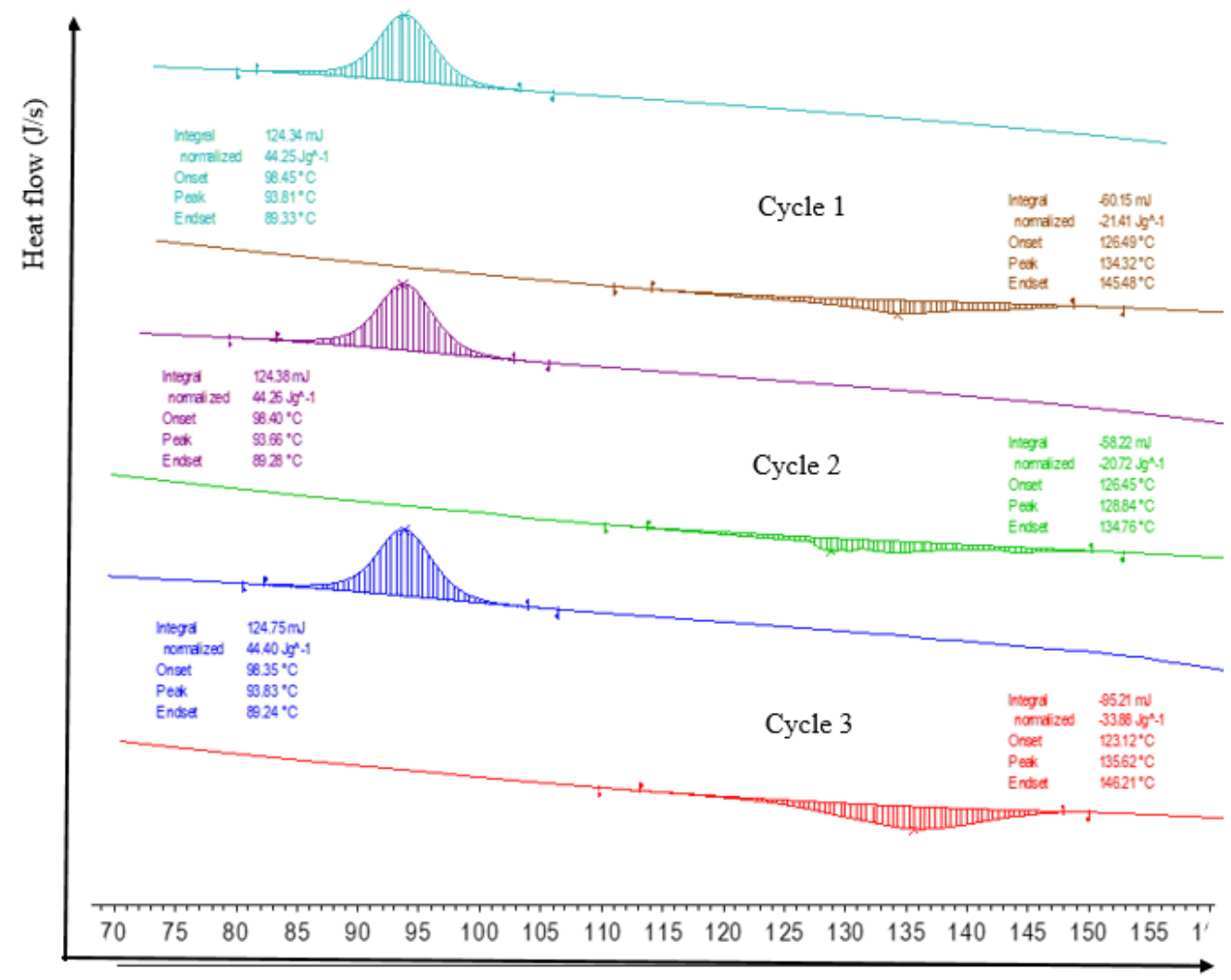

Temperature $\left({ }^{\circ} \mathrm{C}\right)$

Figure 18. Differential Scanning Calorimetry Thermogram of the Used (1 Cycle) Powder

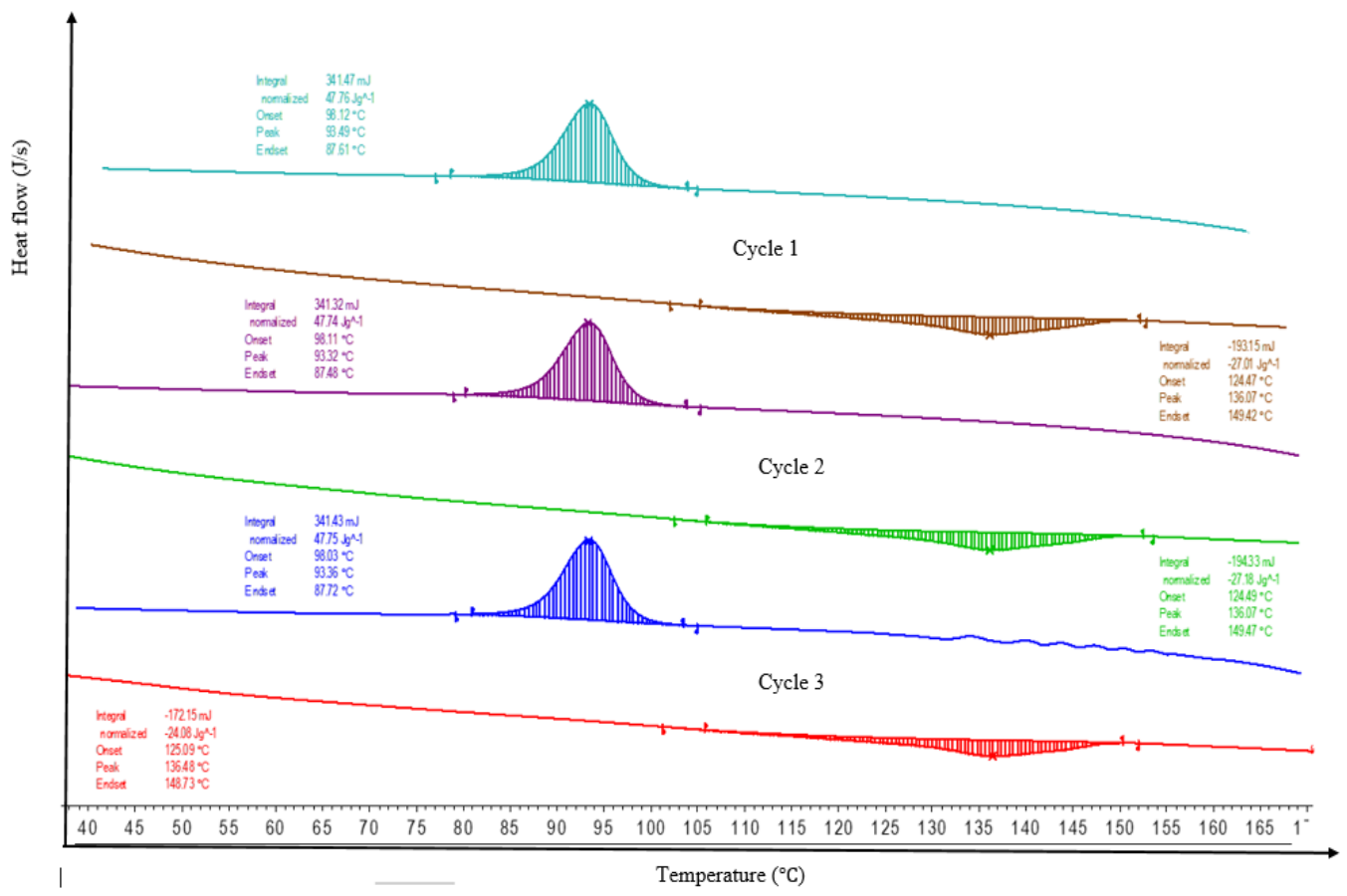

Figure 19. Differential Scanning Calorimetry Thermogram of the Used-Virgin Powder Mixture 
International Journal of Engineering Research and Technology. ISSN 0974-3154, Volume 13, Number 11 (2020), pp. $3342-3358$

(C) International Research Publication House. https://dx.doi.org/10.37624/IJERT/13.11.2020.3342-3358

Table 3. Thermal properties of virgin, used, and used-virgin mixture Laser PP CP 60 polypropylene powder (DSC results)

\begin{tabular}{|c|c|c|c|c|c|c|c|c|}
\hline $\begin{array}{c}\text { Powder } \\
\text { Batch }\end{array}$ & $\begin{array}{c}\text { Peak } \\
\text { melting } \\
\text { point } \\
\left({ }^{\circ} \mathrm{C}\right)\end{array}$ & $\begin{array}{c}\text { The onset of } \\
\text { melting } \\
\text { point }\left({ }^{\circ} \mathrm{C}\right)\end{array}$ & $\begin{array}{c}\text { End-set of } \\
\text { melting } \\
\text { point } \\
\left({ }^{\circ} \mathrm{C}\right)\end{array}$ & $\begin{array}{c}\text { Melting } \\
\text { shoulder } \\
\text { interval } \\
\left({ }^{\circ} \mathrm{C}\right)\end{array}$ & $\begin{array}{c}\text { Peak } \\
\text { crystalliza } \\
\text { tion point } \\
\left({ }^{\circ} \mathrm{C}\right)\end{array}$ & $\begin{array}{c}\text { The onset of } \\
\text { crystallizati } \\
\text { on point } \\
\left({ }^{\circ} \mathrm{C}\right)\end{array}$ & $\begin{array}{c}\text { End-set of } \\
\text { melting } \\
\text { point } \\
\left({ }^{\circ} \mathrm{C}\right)\end{array}$ & $\begin{array}{c}\text { Crystallization } \\
\text { shoulder } \\
\text { interval } \\
\left({ }^{\circ} \mathrm{C}\right)\end{array}$ \\
\hline $\begin{array}{c}\text { Virgin } \\
\text { material }\end{array}$ & 135.59 & 118.83 & 144.56 & 25.73 & 93.46 & 97.79 & 87.60 & 10.19 \\
\hline $\begin{array}{c}\text { Used (aged) } \\
\text { material }\end{array}$ & 132.93 & 125.35 & 142.13 & 16.78 & 93.76 & 98.40 & 89.28 & 9.12 \\
\hline $\begin{array}{c}\text { used-virgin } \\
\text { mixture }\end{array}$ & 136.21 & 124.80 & 149.21 & 24.41 & 93.39 & 98.09 & 87.60 & 10.49 \\
\hline
\end{tabular}

The sintering window $(S W)$ is given by the equation [23]

$$
S W=\left(T_{m}-T_{c}\right)_{\text {onset }}
$$

where the symbols, $T_{m}$ stands for onset melting point, $T_{c}$ onset crystallisation.

The Degree of crystallization (DC) is given by the equation:

$$
D C=\left(\Delta \mathrm{Hm} / \Delta \mathrm{H}^{0}{ }_{m}\right) \times 100 \%
$$

where the symbols, $\Delta \mathrm{H}_{\mathrm{m}}$ stands for experimental melting enthalpy, $\Delta \mathrm{H}^{0}{ }_{\mathrm{m}}$ theoretical melting enthalpy, of the material. The theoretical melting enthalpy of $100 \%$ crystalline polypropylene is equal to $209 \mathrm{~J} / \mathrm{g}$ [18].

Table 4. Calculated sintering window of the virgin powder, used material, and the used-virgin mixture of PP CP 60 Polypropylene Powder from the Results of DSC

\begin{tabular}{|c|c|c|c|}
\hline Powder Batch & $\begin{array}{c}\text { The onset } \\
\text { of melting, } \\
T_{m} \\
\left({ }^{\circ} \mathrm{C}\right)\end{array}$ & $\begin{array}{c}\text { The onset of } \\
\text { crystallization, } \\
T_{c} \\
\left({ }^{\circ} \mathrm{C}\right)\end{array}$ & $\begin{array}{c}\text { Sintering } \\
\text { window, } \\
S W \\
\left({ }^{\circ} \mathrm{C}\right)\end{array}$ \\
\hline Virgin powder & 118.83 & 97.79 & 21.04 \\
\hline Used powder & 125.35 & 98.40 & 26.95 \\
\hline $\begin{array}{c}\text { Used-virgin } \\
\text { powder mixture }\end{array}$ & 124.80 & 98.09 & 26.71 \\
\hline
\end{tabular}

The sintering windows for the new Laser PP CP 60 polypropylene powder increased from $21.04^{\circ} \mathrm{C}$ (virgin material) to $26.95^{\circ} \mathrm{C}$ (used material). The addition of $50 \%$ virgin material into $50 \%$ used material decreased the sintering window slightly from $26.95^{\circ} \mathrm{C}$ to $26,71^{\circ} \mathrm{C}$. The changes are associated with degradation and cross-linking of the materials, which shifts the thermal properties of polymers [14]. The sintering window of the new Laser PP CP 60 polypropylene powder is lower than the sintering window for PA12 powder, which ranges from $32^{\circ} \mathrm{C}$ to $34^{\circ} \mathrm{C}$ [7]. It is, therefore, expected that difficulties will be experienced when regulating the cooling rate of the printed parts using the new Laser PP CP 60 polypropylene powder [23]. It also explains the problems of curling that were observed with the new material. However, the problem of curling can be resolved by determining the most suitable extraction chamber temperature for the new polymeric material. Schmid et al. [23], suggest that homogeneous and stable thermal conditions reduce the curling and warpage issues associated with polymeric materials with narrow sintering windows.

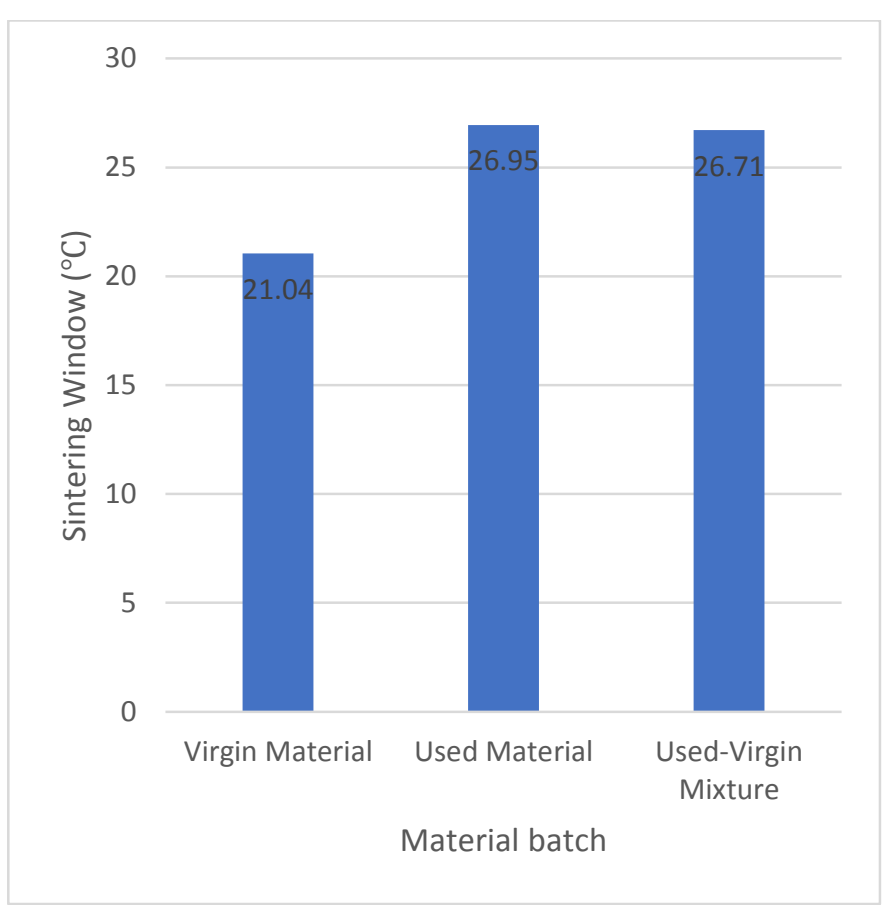

Figure 20. The Trend of the Sintering Windows for Virgin, Used, and Used-Virgin Mixture Powders

Table 5. Calculated Degree of Crystallisation of the Virgin, Used, and Used-Virgin mixture of Laser PP CP 60 Polypropylene Powders from the Results of DSC

\begin{tabular}{|c|c|c|c|}
\hline $\begin{array}{c}\text { Powder } \\
\text { Batch }\end{array}$ & $\begin{array}{c}\text { Experimental } \\
\text { Melting } \\
\text { Enthalpy of } \\
\text { the Material }\end{array}$ & $\begin{array}{c}\text { Theoretical } \\
\text { Melting } \\
\text { Enthalpy of } \\
\text { the Material }\end{array}$ & $\begin{array}{c}\text { Degree of } \\
\text { Crystallisation } \\
\text { of the Material }\end{array}$ \\
\hline $\begin{array}{c}\text { Virgin } \\
\text { material }\end{array}$ & $29.10 \mathrm{~J} / \mathrm{g}$ & $209 \mathrm{~J} / \mathrm{g}$ & $13.92 \%$ \\
\hline $\begin{array}{c}\text { Used } \\
\text { material }\end{array}$ & $25.34 \mathrm{~J} / \mathrm{g}$ & $209 \mathrm{~J} / \mathrm{g}$ & $12.12 \%$ \\
\hline $\begin{array}{c}\text { Used- } \\
\text { virgin } \\
\text { mixture }\end{array}$ & $26.09 \mathrm{~J} / \mathrm{g}$ & $209 \mathrm{~J} / \mathrm{g}$ & $12.48 \%$ \\
\hline
\end{tabular}




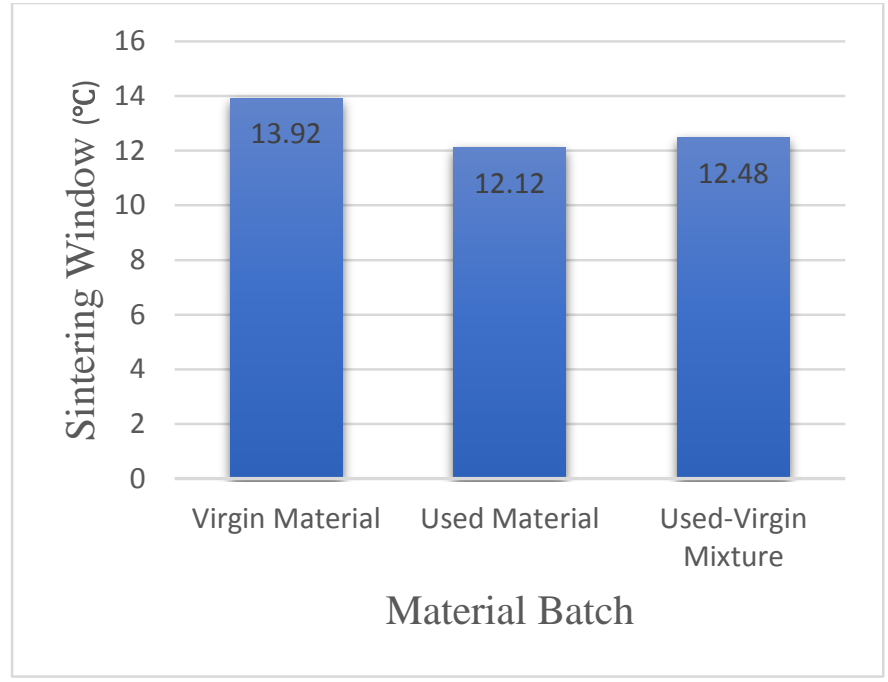

Figure 21. The Trend for the Degree of Crystallisation of the Virgin, Used, and Used-Virgin Mixture Powders

It was also observed that the degree of crystallinity of virgin material decreased slightly from $13.92 \%$ to $12.12 \%$ after printing a single cycle. This might have been due to breakdown of the long carbon chains. The findings contradict a research by Dadbakhsh et al., [10], which suggests that powder crystallinity of PA 12 materials increases with aging. This raises speculation that PA 12 and polypropylene powders degrade differently when subjected to high processing parameters. However, a study by Chen et al., [22], illustrates that crystallinity of original PA 12 powder decreases from 46.94 to $44.22 \%$ when aged, which is consistent with the present work. The magnitude of crystallinity increased slightly to $12.48 \%$ by the addition of $50 \%$ virgin material, probably due to restoration of long carbon chains.

\subsection{The Thermogravimetric (TGA) Analysis}

The TGA analysis was used to determine the degradation and break up temperature $\left(\mathrm{T}_{\mathrm{d}}\right)$ of the three polypropylene powder batches (Virgin Material, Used Material, and Used-virgin Mixture). Figures 22, 23, and 24 illustrate the thermogravimetric thermogram of the three batches of Laser PP CP 60 Polypropylene Powder, while Table 5 and Figure 25 summarizes the degradation temperature $\left({ }^{\circ} \mathrm{C}\right)$ thread of the powders.

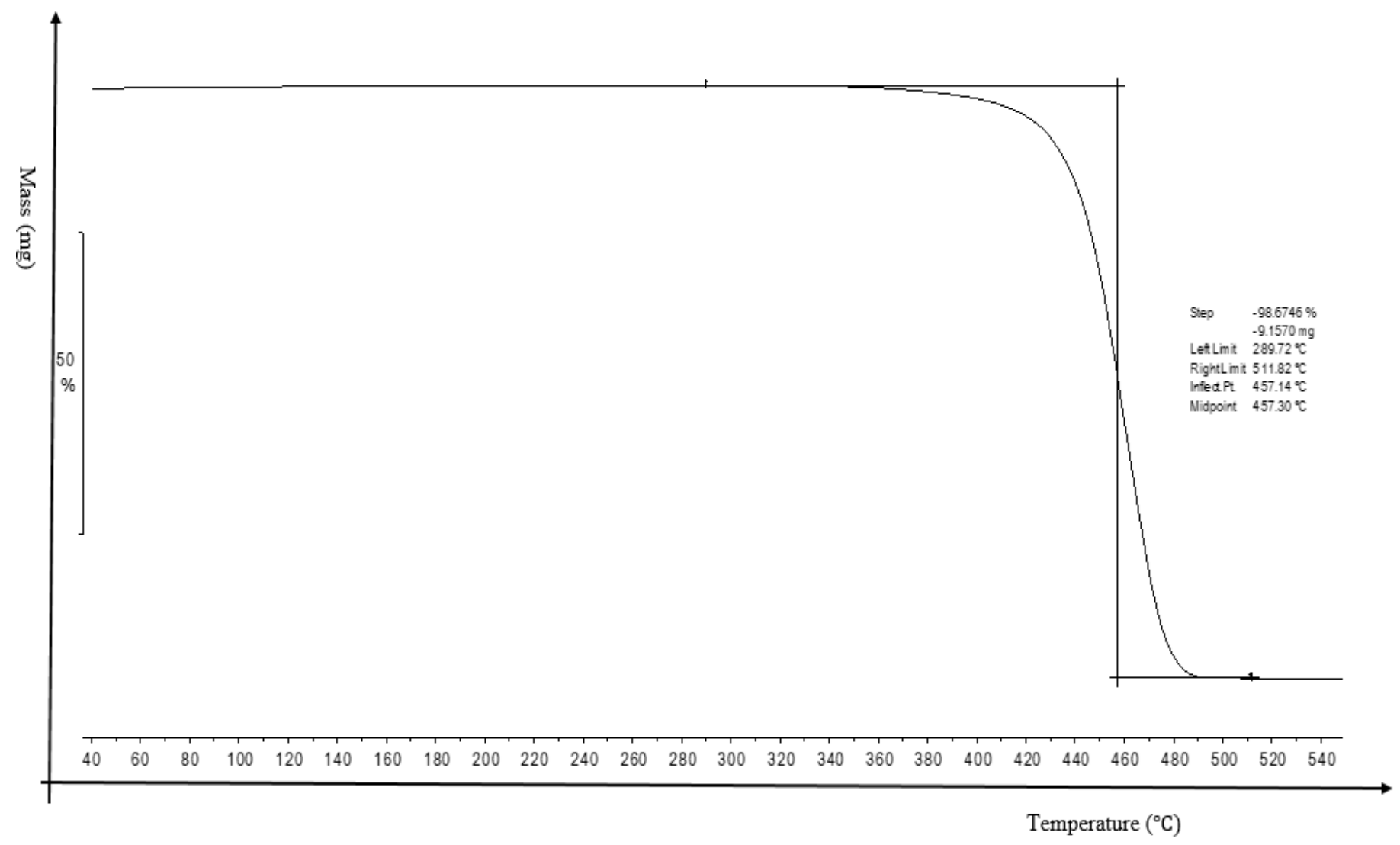

Figure 22. Thermogravimetric Thermogram of the Virgin Laser PP CP 60 Polypropylene Powder 
International Journal of Engineering Research and Technology. ISSN 0974-3154, Volume 13, Number 11 (2020), pp. 3342-3358

(C) International Research Publication House. https://dx.doi.org/10.37624/IJERT/13.11.2020.3342-3358

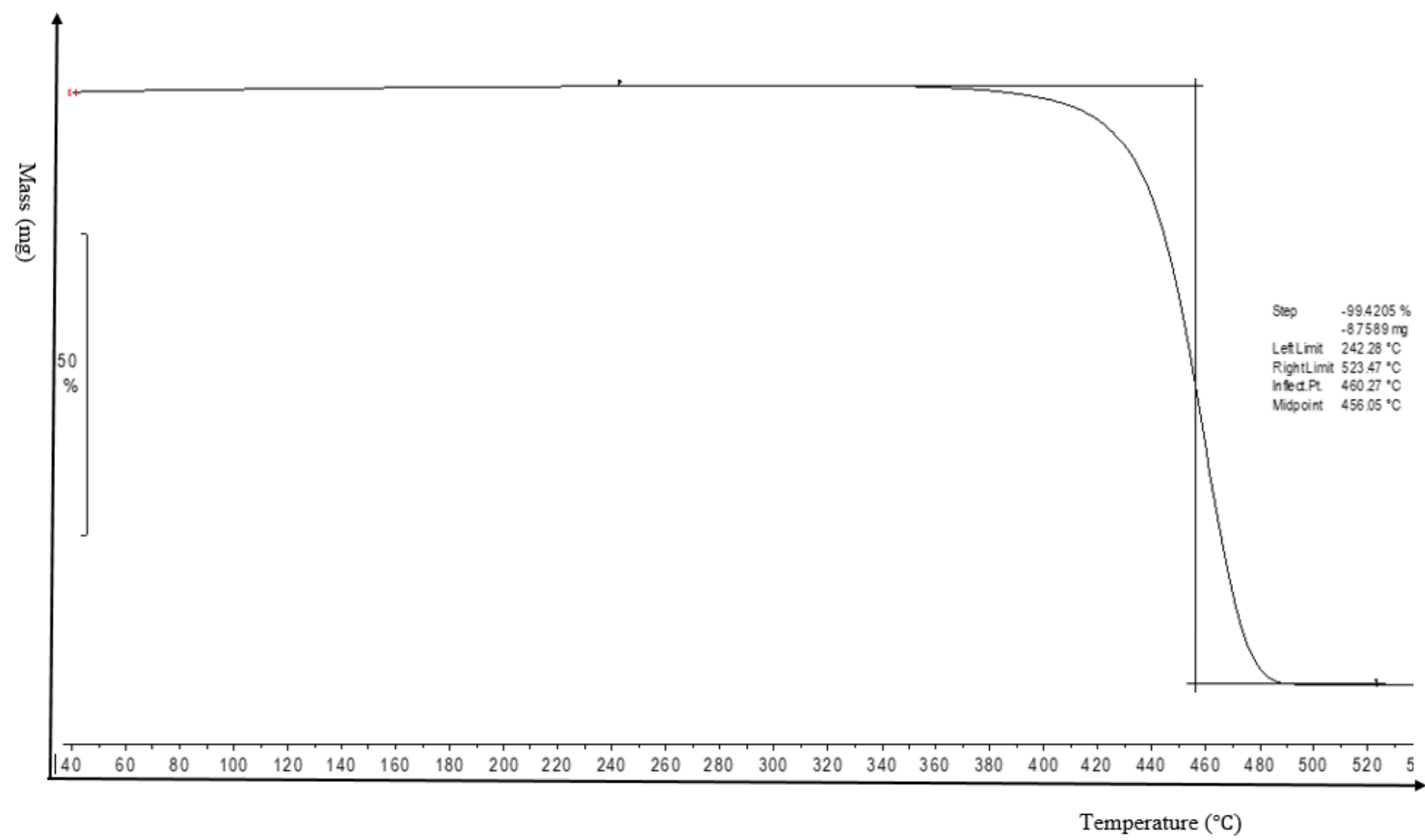

Figure 23. Thermogravimetric Thermogram of the Used (1 Cycle) Laser PP CP 60 Polypropylene Powder

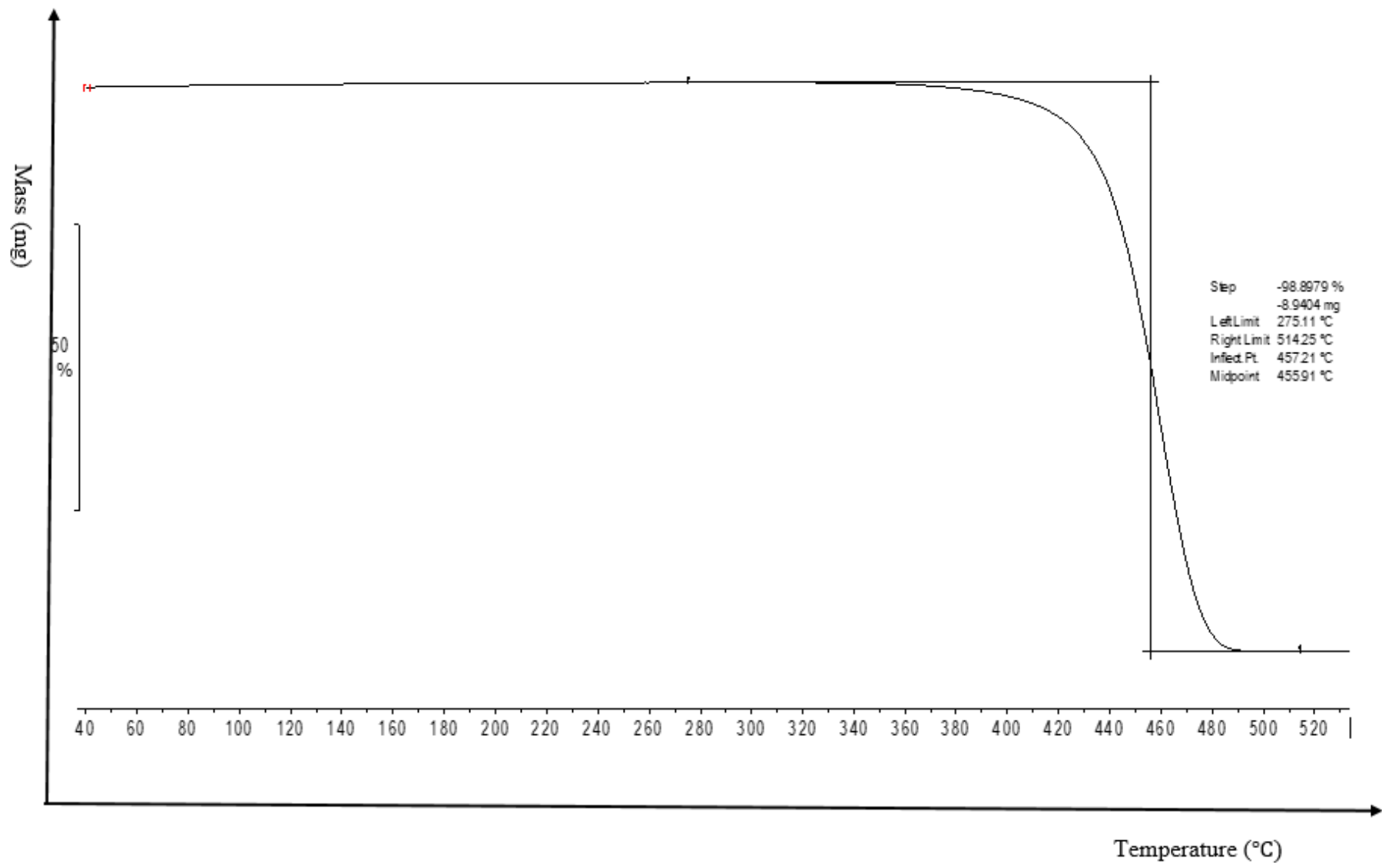

Figure 24. Thermogravimetric Thermogram of the Used-Virgin Material Powder 
Table 6.The degradation temperature of the virgin, used, and used-fresh mixture of Laser PP CP 60 Polypropylene Powder

\begin{tabular}{|c|c|}
\hline Powder Batch & The Degradation Temperature $\left({ }^{\circ} \mathrm{C}\right)$ \\
\hline Virgin powder & 457.30 \\
\hline Used powder & 456.05 \\
\hline $\begin{array}{c}\text { Used-Fresh } \\
\text { mixture powder }\end{array}$ & 455.91 \\
\hline
\end{tabular}

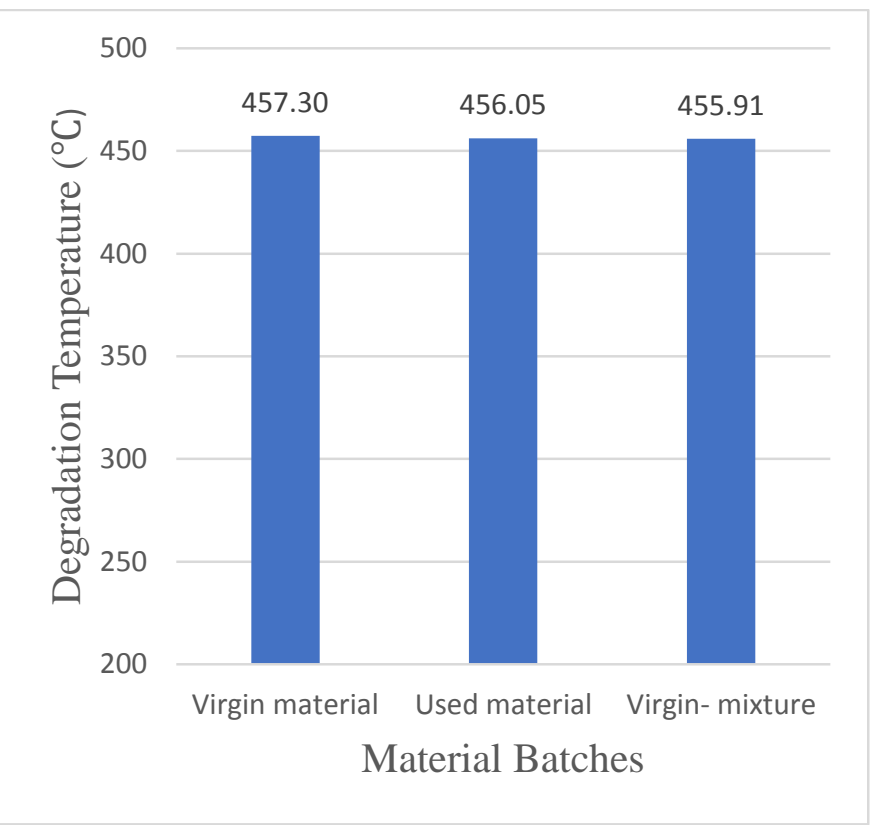

Figure 25. The Trend for the Degradation Temperature of the Virgin, Used, and Used-Virgin Mixture Powder

The degradation temperature $\left(\mathrm{T}_{\mathrm{g}}\right)$ of Virgin Laser PP CP 60 polypropylene powder was obtained as $457.30^{\circ} \mathrm{C}$. The used and used-fresh powder batches had slightly lower degradation temperatures $\left(\mathrm{T}_{\mathrm{g}}\right)$ of $456.06{ }^{\circ} \mathrm{C}$ and $455.91{ }^{\circ} \mathrm{C}$, respectively. The high temperatures of degradation and break-up of the three batches of Laser PP CP 60 polypropylene powder illustrate that this polyolefin can be employed in SLS since the process progresses at a temperature of about $125^{\circ} \mathrm{C}$. Therefore, material will not degrade and break-up during processing.

\subsection{Melt Flow Index (MFI) Testing}

The MFI testing was used to determine the flowability and viscosity of the three batches of powder, with the results shown in and Figure 26. Table 6 illustrates the average values from a total of six measurements for each of the powder batches.

Table 7. The values of MFI for the Virgin, Used and UsedVirgin Mixture Powders

\begin{tabular}{|c|c|}
\hline Powder Batch & MFI value g/10min \\
\hline Virgin material & 6.1 \\
\hline Used material & 6.5 \\
\hline Used-virgin mixture & 6.4 \\
\hline
\end{tabular}

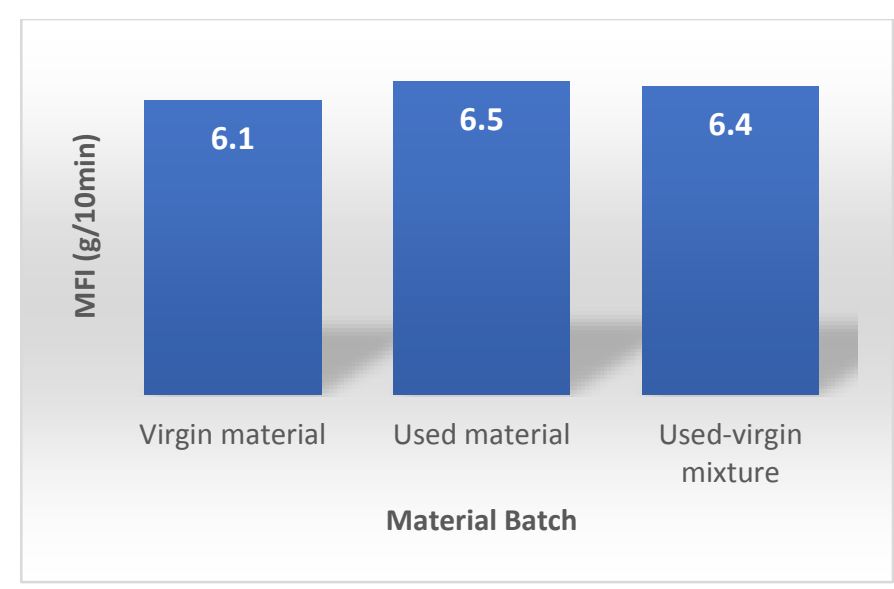

Figure 26. The Trend for the MFI of the Virgin, Used, and Used-Virgin Mixture of Powders

A virgin Laser PP CP 60 polypropylene material had a low melting flow index of $6.1 \mathrm{~g} / 10 \mathrm{~min}$, which increased slightly to $6.5 \mathrm{~g} / 10 \mathrm{~min}$ after one recycle. The addition of $50 \%$ virgin material to the recycled powder slightly reduced the MFI of used powder to $6.4 \mathrm{~g} / 10 \mathrm{~min}$. These values all show the Laser PP CP 60 powder to be highly viscous and will, therefore, have a low flowability.

\subsection{CONCLUSION AND RECOMMENDATIONS}

\subsection{Conclusions}

The particle size and morphology, sintering window, degree of crystallinity, degradation temperature, and melt flow rate of virgin, aged, and mixed Laser PP CP 60 polypropylene powder material were examined in the study. The main findings of the study were:

1. All the three batches of powder considered showed poor (not 100\% spherical), but allowable morphology and particle size distribution. It was also concluded that the used Laser PP CP 60 polypropylene powder showed presence of agglomeration, which can be ameliorated by mixing with virgin material and proper mixing.

2. The sintering windows for all three batches of Laser PP CP 60 polypropylene were lower than that for polyamide 12 polymer $\left(32^{\circ} \mathrm{C}-34^{\circ} \mathrm{C}\right)$, which might have contributed to the high shrinkage rates observed due to difficulties in regulating the cooling rate of printed parts that led to curling.

3. The degree of crystallinity of virgin Laser PP CP 60 decreased from $13.92 \%$ to $12.12 \%$ after a single printing cycle and then increased to $12.48 \%$ upon the addition of $50 \%$ virgin material.

4. The high degradation and break-up temperatures of the three powder batches makes the material suitable for SLS processing.

5. The low values of MFI of the three melt powder batches imply high viscosities of Laser PP CP 60, which will thus 
have poor flowability and may explain the difficulties experienced when processing the powder.

In summary, Laser PP CP 60 polypropylene powder exhibits high degradation and break-up temperatures, which indicates that the material is not expected to experience significant deterioration during SLS processing. However, all the powder batches exhibited irregularly shaped particles with broad particle distribution, low MFIs and narrow sintering windows, which indicate potential for poor processability due to difficulties of spreading the powders and problems of shrinkage.

\subsection{Recommendations for further work}

1. The SEM images revealed that the material did not have presence of flow agents, which might explain the flowability difficulties of the powder. Therefore, the best flow/antistatic agents and their proportion of the new material, which can be used without compromising mechanical and physical properties of the material should be established.

2. Further testing of the powder is recommended to establish the trend of degradation with higher reuse cycles in order to determine the limit of recycling, while tagging the most critical of the parameters tested here in this respect.

\section{REFERENCES}

[1] Wong, K. V., \& Hernandez, A. 2012. A review of additive manufacturing. International scholarly research notices, 1(1), pp. 1-10.

[2] Schmid, M., Amado, A., \& Wegener, K. 2015. Polymer powders for selective laser sintering (SLS). In AIP Conference Proceedings, 1664(1), pp. 160009-160015.

[3] Goodridge, R.D., Tuck, C.J. and Hague, R.J.M., 2012. Laser sintering of polyamides and other polymers. Progress in Materials science, 57(2), pp.229267.

[4] Drummer, D., Wudy, K., \& Drexler, M. 2014. Influence of energy input on the degradation behavior of plastic components manufactured by selective laser melting. Physics Procedia, 56(C), pp. 176-183.

[5] Wudy, K., Drummer, D. and Drexler, M., 2014, May. Characterization of polymer materials and powders for selective laser melting. In AIP Conference Proceedings, 1593(1), pp. 702-707.

[6] Schmid, M. and Wegener, K., 2016. Additive manufacturing: polymers applicable to laser sintering (LS). Procedia Engineering, 149(1), pp.457-464.

[7] Marin, T.M., 2017. Selective laser sintering of polyolefins (Master's thesis).

[8] Hesse, N., Dechet, M.A., Bonilla, J.S.G., Lübbert, C., Roth, S., Bück, A., Schmidt, J. and Peukert, W., 2019. Analysis of Tribo-Charging during Powder Spreading in
Selective Laser Sintering: Assessment of Polyamide 12 Powder Ageing Effects on Charging Behavior. Polymers, 11(4), pp. 597-609.

[9] K. Dotchev \& W. Yusoff, 2009. "Recycling of polyamide 12 based powders in the laser sintering process", Rapid Prototyping Journal, 15 (3), pp.192-203.

[10] Dadbakhsh, S., Verbelen, L., Verkinderen, O., Strobbe, D., Van Puyvelde, P., \& Kruth, J. P. 2017. Effect of PA12 powder reuse on coalescence behaviour and microstructure of SLS parts. European Polymer Journal, 92(1), pp. 250-262.

[11] T.J. Gornet, K.R. Davis, T.L. Starr, K.M. Mulloy. 2002. Characterization of selective laser sintering materials to determine process stability. In Solid Freeform Fabrication Symposium, Austin, 1(1), pp. 546-553.

[12] Zarringhalam, H., Hopkinson, N., Kamperman, N. F., \& De Vlieger, J. J. 2006. Effects of processing on microstructure and properties of SLS Nylon 12. Materials Science and Engineering, 435(1), pp.172-180.

[13] Drummer, D., Harder, R. G., Witt, G., Wegner, A., Wudy, K., \& Drexler, M. 2015. Long-term Properties of Laser Sintered Parts of Polyamide 12-Influence of Storage Time and Temperature on the Aging Behavior. International Journal of Recent Contributions from Engineering, Science \& IT (iJES), 3(1), pp. 20-27.

[14] Kuehnlein, F., Drummer, D., Rietzel, D., \& Seefried, A. 2010. Degradation Behavior and Material Properties of PA 12 Plastic Powders Processed by Powder Based Additive Manufacturing Technologies. Annals of DAAAM for 2010 \& Proceedings of the 21st International DAAAM Symposium, 21(1), pp. 1-2.

[15] Berretta, S., Ghita, O., \& Evans, K. E. 2014. Morphology of polymeric powders in Laser Sintering (LS): From Polyamide to new PEEK powders. European Polymer Journal, 59(1), pp. 218-229.

[16] Bourell, D. L., Watt, T. J., Leigh, D. K., \& Fulcher, B. 2014. Performance limitations in polymer laser sintering. Physics Procedia, 56(1), pp. 147-156.

[17] Wudy, K., Drummer, D., Kühnlein, F., \& Drexler, M. 2014. Influence of degradation behavior of polyamide 12 powders in laser sintering process on produced parts. In AIP Conference Proceedings, 1593(1), pp. 691-695).

[18] Wypych, G. 2012. Handbook of polymers, ChemTec Publishing, Toronto.

[19] N. Mys, A. Verberckmoes \& L. Cardon. 2018. Expanding the material palette for Selective Laser Sintering: two production techniques for spherical powders. International Conference on Polymers and Moulds Innovations-PMI,1(1), pp. 1-7.

[20] Schmidt, J., Dechet, M. A., Bonilla, J. G., Hesse, N., Bück, A., \& Peukert, W. 2019. Characterization of polymer powders for selective laser sintering. In proceedings of the 30th Annual International Solid Freeform Fabrication Symposium, 30(1), pp. 779-89. 
[21] Sagar, M. B., \& Elangovan, K. 2017. Consolidation \& Factors Influencing Sintering Process in Polymer Powder Based Additive Manufacturing. MS\&E, 225(1), 012075012084.

[22] Chen, P., Wu, H., Zhu, W., Yang, L., Li, Z., Yan, C., ... \& Shi, Y. 2018. Investigation into the processability, recyclability and crystalline structure of selective laser sintered Polyamide 6 in comparison with Polyamide 12. Polymer Testing, 69(1), 366-374.

[23] Schmid, M., Kleijnen, R., Vetterli, M., \& Wegener, K. 2017. Influence of the origin of polyamide 12 powder on the laser sintering process and laser sintered parts. Applied Sciences, 7(5), 462-479.

[24] Drummer, D., Rietzel, D., \& Kühnlein, F. 2010. Development of a characterization approach for the sintering behavior of new thermoplastics for selective laser sintering. Physics Procedia, 5(1), 533-542.

[25] Aldahsh, S. 2013. Dependence of SLS Parameters on Thermal Properties of Composite Material of Cement with Polyamide 12. Journal of Applied Mechanical Engineering, 2(5), 1-7.

[26] Mys, N., Verberckmoes, A., \& Cardon, L. 2016. Processing of syndiotactic polystyrene to microspheres for part manufacturing through selective laser sintering. Polymers, 8(11), 383-399. 